\title{
Sensing Shallow Structure and Traffic Noise with Fiber-optic Internet Cables in an Urban Area
}

\author{
Zhenghong Song $^{1,2} \cdot$ Xiangfang Zeng $^{1} \cdot$ Jun $\mathrm{Xie}^{1} \cdot$ Feng Bao $^{1} \cdot$ Gongbo Zhang $^{1}$
}

Received: 20 June 2021 / Accepted: 26 October 2021 / Published online: 19 November 2021

(c) The Author(s), under exclusive licence to Springer Nature B.V. 2021

\begin{abstract}
Distributed acoustic sensing (DAS) is a novel seismic observation system developed in recent years that can realize ultrahigh density observations and has attracted extensive attention in the field of seismology. DAS uses fiber-optic cables as sensing units, which are easy to incorporate with urban telecommunication fiber-optic cables for seismological observations. Compared with seismometers, DAS has the advantages of being rapidly deployed and recyclable, being able to acquire dense observations at low cost, and convenient data collection. In this study, a $5.2 \mathrm{~km}$ long telecom fiber-optic internet cable was utilized as a DAS array in an urban area to record ambient noise, and the noise cross-correlation function (NCF) was calculated. There are two different distribution types of ambient noise sources along the cable, regular along-road trucks (Taihe Road) and complex ambient noise, including human activities and traffic sources along and across the Jinniu road. In the first case, we constructed a 2D S-wave velocity model down to $100 \mathrm{~m}$ depth and a low-velocity zone was revealed. The S-wave model well explained the traffic signal along the Taihe road and the low-velocity zone is also consistent with the results obtained from co-located geophone arrays. In the second case, due to the complexity of the traffic noise distribution, empirical Green's functions were barely achieved. Therefore, we performed a synthetic test obtaining different NCFs with different source distributions, and two specific cases that dominate the NCF results were matched. Finally, we obtained the traffic noise distribution along the road, which is consistent with the power spectra density of the ambient noise. In conclusion, by combining DAS and urban fiber-optic internet cables with urban traffic noise, we can effectively reveal the traffic activities and image shallow structures with high resolution, which could offer a reference for urban construction and disaster prevention.
\end{abstract}

Keywords Distributed acoustic sensing · Urban area · Ambient noise tomography ·

Ambient noise source distribution

\section{Article Highlights}

- DAS turns the urban fiber-optic internet cables into ultra-dense permanent seismic observation arrays

- We revealed a high-resolution shallow structure using urban fiber-optic internet cables

- We obtained the distribution of traffic activities along the road

Extended author information available on the last page of the article 


\section{Introduction}

The shallow $(100 \mathrm{~m})$ subsurface has been gradually utilized (e.g., Bobylev 2010), and an increasingly large number of infrastructure constructions require high-precision underground maps for design. Pipes are laid beneath the roads in cities, and water leakage often causes the loss of subgrade materials and the formation of underground cavities, which then causes the ground to collapse. High-resolution images of shallow structures could help the planning of buildings and the utilization of underground space, the simulation of ground motions (Bonnefoy-Claudet et al. 2006), and the identification of sinkholes (Tran et al. 2013), which are of great significance for city development. Seismological methods have been widely used for imaging and monitoring the subsurface by its high precision (Ma and Qian 2020), and remarkable results have been achieved (e.g., Foti et al. 2011; Krawczyk et al. 2012; Nakata et al. 2011, 2015, Bora et al. 2020; Wang et al. 2021a).

Seismic methods for imaging subsurface structures include reflection imaging (e.g., Bruno \& Rapolla 1999), refraction imaging (e.g., Azwin et al. 2013), the horizontal-tovertical spectral ratio method (HVSR, e.g., Bao et al. 2018), and surface wave imaging (e.g., Xia et al. 1999, 2003, 2007; Foti et al. 2011; Li et al. 2016a; Liang et al. 2019; Zhang et al. 2019; Mi et al. 2020; Zhou et al. 2021; Chen et al. 2021). Surface wave methods, including active source and passive source imaging, have been widely used because of their high signal-to-noise ratio (SNR) in the field recording. The shallow structure can be obtained from the inversion of dispersion curve or waveform of surface waves. Many approaches have been proposed to measure the dispersion curves (e.g., Chapman, 1978; Mcmechan and Yedlin 1981; Xia et al. 2007; Luo et al. 2008; Wang et al. 2019; Li et al. 2021). One of the most popular methods is the multi-channel analysis of surface wave (MASW, Park et al. 1999, 2007), which measures phase velocities based on phase differences across array. Active sources, such as hammers and explosives, are used in geological exploration to provide high-quality data, however, in the urban environment, its deployment is limited due to high cost or community impact. Passive sources including earthquake and ambient noise are also used for tomography. Ambient noise tomography (ANT), which calculates the cross-correlation function of continuous ambient noise records and stacks them to extract surface wave signals for imaging (Bensen et al. 2007), became popular since early 2000. Since the vertical resolution of surface wave tomography depends on signal wavelength, small station spacing is needed to capture short wavelength/high-frequency surface wave signal, which is sensitive to shallow structure. Therefore, most studies relied on dense arrays with the spacing ranges of hundreds of meters to kilometers. Many high-quality ANT results have been obtained in various cities. For instance, Boué et al. (2016) successfully recovered the fundamental and higher modes Rayleigh and Love wave signals from the dense Metropolitan seismic observation network (MeSO-net) in Kanto basin, Japan. Lin et al. (2013) conducted a high-resolution shallow structure beneath a dense array in Long Beach, Los Angles.

However, the ambient noise tomography is strongly affected by the distribution of the noise source (e.g., Galetti and Curtis, 2012; Yao et al. 2009; Zeng et al. 2010; Retailleau et al. 2021). In urban areas, high frequency $(>1 \mathrm{~Hz})$ ambient noise wavefield is dominated by the traffic-related signal, which is heterogeneous. Determining the distribution of noise source help to understand signals emerging on the noise cross-correlation function (NCF) and reduce contaminant from precursor signals (e.g., Lehujeur et al. 2016; Zeng et al. 2017). The types and distributions of vehicles have been identified and analyzed from ambient noise by predecessors (e.g., Martin et al. 2018; Dumont et al. 2020; Lindsey et al. 
2020). Schippkus et al. (2020) used the large-N arrays in the Vienna Basin to collect environmental noise signals and analyzed the characteristics of urban environmental noise, including the railway track, windmills and oil pumpjacks. Through the ambient noise analysis, researchers monitored the changes of the urban traffic and human activities during the lockdown due to COVID-19 pandemic (Lecocq et al. 2020; Roy et al. 2021; Kuponiyi et al. 2021). Monitoring traffic activity can also provide information for urban construction and management (e.g., Li et al. 2016b).

Although the dense arrays consisting of hundreds to thousands of short-period geophones have been successfully used in several cities, deployment cost is significant and it is difficult to maintain for long-term monitoring. Distributed acoustic sensing (DAS) is a novel seismic observation system with ultrahigh density that has recently been applied in the seismological community (Zhan 2020). DAS uses fiber-optic cables as sensing units directly, which can achieve thousands to ten thousand of kilometers permanent observation with the spacing in the meter scale (Parker et al. 2014). It has been verified that DAS can obtain a high-resolution velocity model of the shallow structure through independent experiments involving buried optical cables in different environments (e.g., Dou et al. 2017; Zeng et al. 2017; Parker et al. 2018a, b; Song et al. 2020; Lin et al. 2020). Cities have dense fiber-optic networks, and DAS technology can be easily utilized to turn them into ultra-dense seismic arrays. Compared with seismometer and geophone, DAS greatly improves equipment deployment and recovery efficiency and reduces deployment costs and challenges in the urban areas. A series of achievements have been made based on the existing telecommunication cables in the urban environment, such as earthquake signal identification (Lindsey et al. 2017; Nayak \& Ajo-Franklin, 2021), large-volume airgun signal detection (Song et al. 2021), thunder signal monitoring (Zhu and Stensrud 2019), footstep detection (Jakkampudi et al. 2020), near-surface characterization (Spica et al. 2020; Fang et al. 2020), human and vehicle activity monitoring (Lindsey et al. 2020; Wang et al. 2020, 2021b). These experiments have well demonstrated that DAS with existing urban fiberoptic cables are capable of signal detection and is expected to construct the high-resolution shallow structure. Ajo-Franklin et al. (2019) successfully imaged the high-resolution shallow structure beneath farmland using telecommunication fiber-optic cables. However, for the complex urban noise environment, the use of telecommunication fiber-optic cables for high-resolution shallow structure imaging has yet to be carried out.

In this study, a $5.2 \mathrm{~km}$ telecom fiber-optic internet cable is used to record ambient noise in an urban area, and we constructed the subsurface structure based on DAS and analyzed the distribution of ambient noise sources along the fiber-optic cable. First, we introduced the observation system and calculated the NCF along the DAS array. Then, the velocity structure and traffic noise distribution were calculated based on the NCFs results. Finally, we discussed the feasibility of combining urban telecommunication fiber-optic cables with DAS for urban structure imaging.

\section{Data and Methods}

\subsection{Data Acquisition}

This experiment was carried out in Binchuan County, located in the Binchuan Basin, a pull-apart basin in southwestern China, between the Chenghai fault and Honghe fault. The faults in this region are active, earthquake events occur frequently, and many studies have been performed in this region based on dense arrays (e.g., Sun et al. 2019; She 
et al. 2019; Zhang, et al. 2020a). In our experiment, a $5.2 \mathrm{~km}$ long fiber-optic internet cable belonging to the Binchuan County Mobile Company and laid along Taihe Road and Jinniu Road (Fig. 1) was used. Taihe Road is a main traffic trunk road, where large trucks are common, while Jinniu Road is located inside the city, where the traffic is dominated by small private cars, and there are many intersections. The cable is loosely laid in a polyvinyl chloride conduit casing under the sidewalk, in contact with the soil, and buried to a depth of approximately $30 \mathrm{~cm}$. Manholes were set at an interval of approximately $100 \mathrm{~m}$, and the conduit was cemented (Wang et al. 2021c). A Helios ${ }^{\circledR}$ Theta DAS interrogator provided by Fotech Group Limited was used for data acquisition, and we set the sampling rate at $500 \mathrm{~Hz}$, the channel spacing at $7.5 \mathrm{~m}$, and the gauge length at $10.9 \mathrm{~m}$. After $16 \mathrm{~h}$ of continuous acquisition, $86 \mathrm{~GB}$ of strain data were obtained including both the daytime and the nighttime (2019-12-03 16:00-2019-12-04 8:00, local time). A 10-min record (6:00-6:10 PM, local time) of CH100 was used to compute spectrum (Fig. 2). As Fig. 2 shows, the frequency range of the noise signal is 1-30 Hz that is consistent with previous studies (Lindsey et al. 2020; Guan et al. 2021). However, the noise level significantly varies across the array. The power spectral densities (PSD) of both daytime (6:00-6:10 PM, local time) and nighttime (2:00-2:10 AM, local time) were computed and shown in Fig. 3. Due to the traffic of heavy trucks, the noise levels of channels along the Taihe Road are much stronger in both the daytime and the nighttime, while the Jinniu Road is located in an urban area, and the noise level significantly changes from day to night. The noise levels of $\mathrm{CH} 440-\mathrm{CH} 450$ and $\mathrm{CH} 490$ CH530 are relatively high, corresponding to intersections, and CH600-CH650 may be influenced by other strong localized noise related to human activities. The noise levels of channels in the Jinniu Road are much weaker in nighttime, which is not conducive to ANT (Zeng et al. 2017).

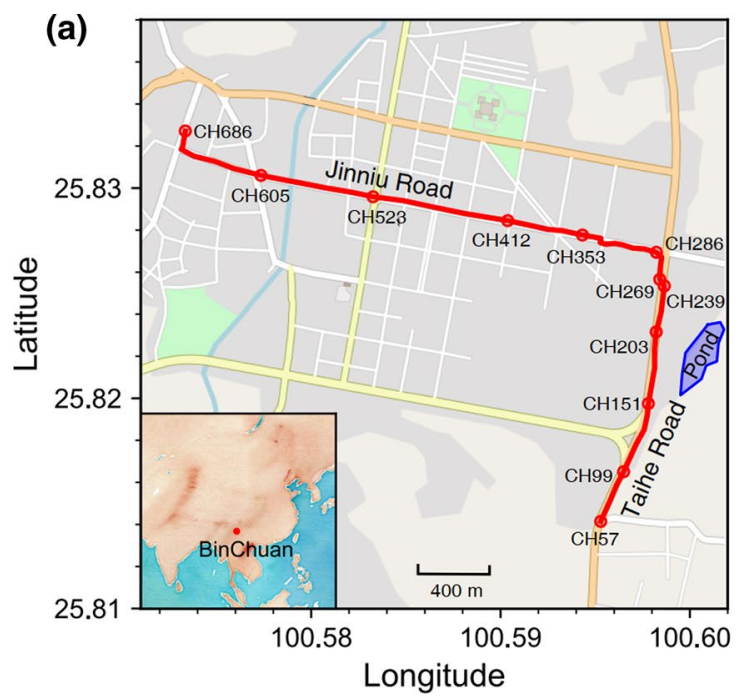

(b)

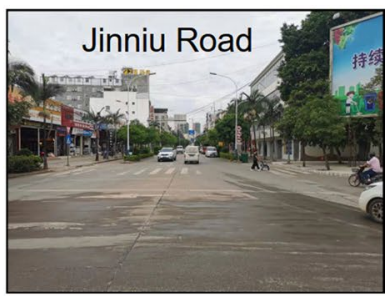

(c)

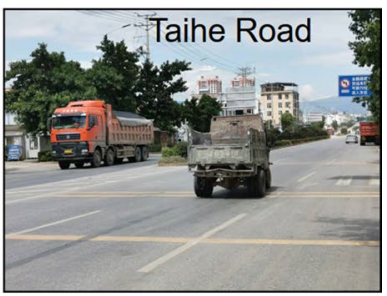

Fig. 1 a The location of the experiment. The red line indicates the fiber-optic cable. The blue area is a pond. $\mathbf{b}$ and $\mathbf{c}$ Photos of Jinniu Road and Taihe Road, respectively 

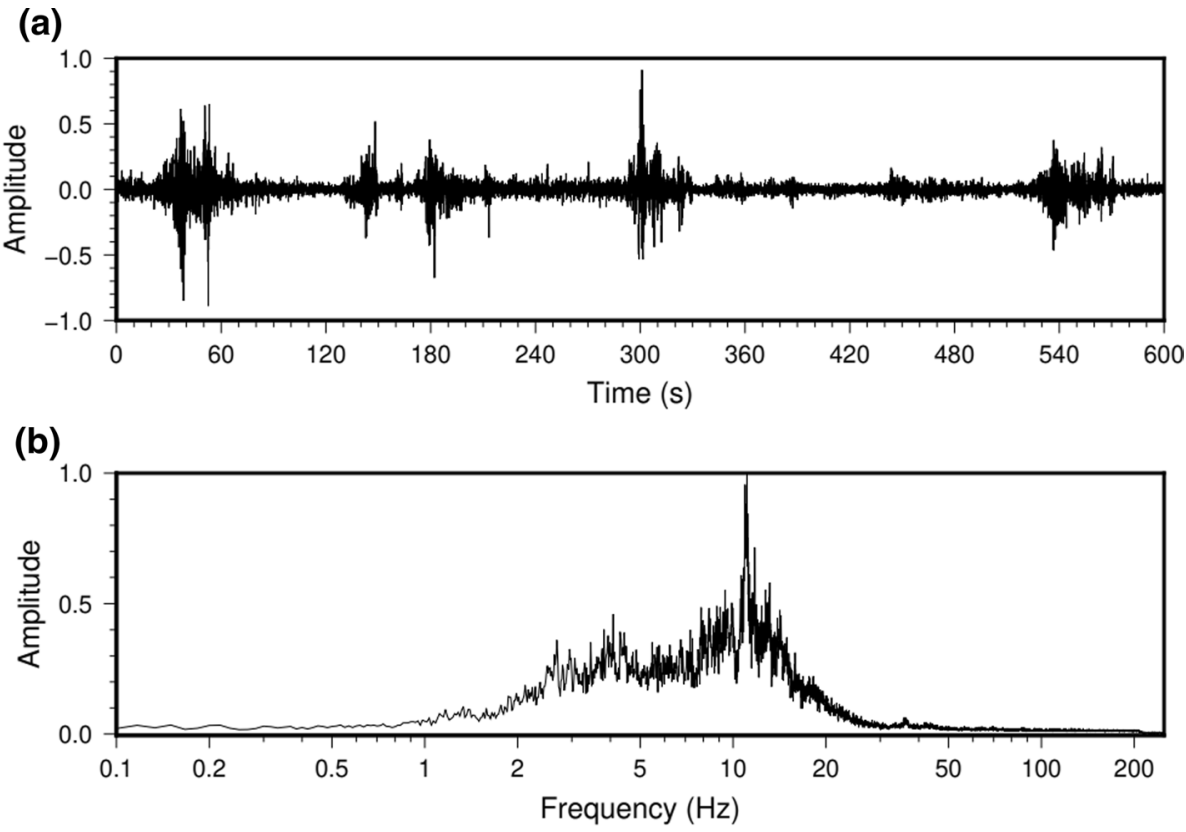

Fig. 2 Ten-minute ambient noise waveform (a) and its spectrum (b) of CH100
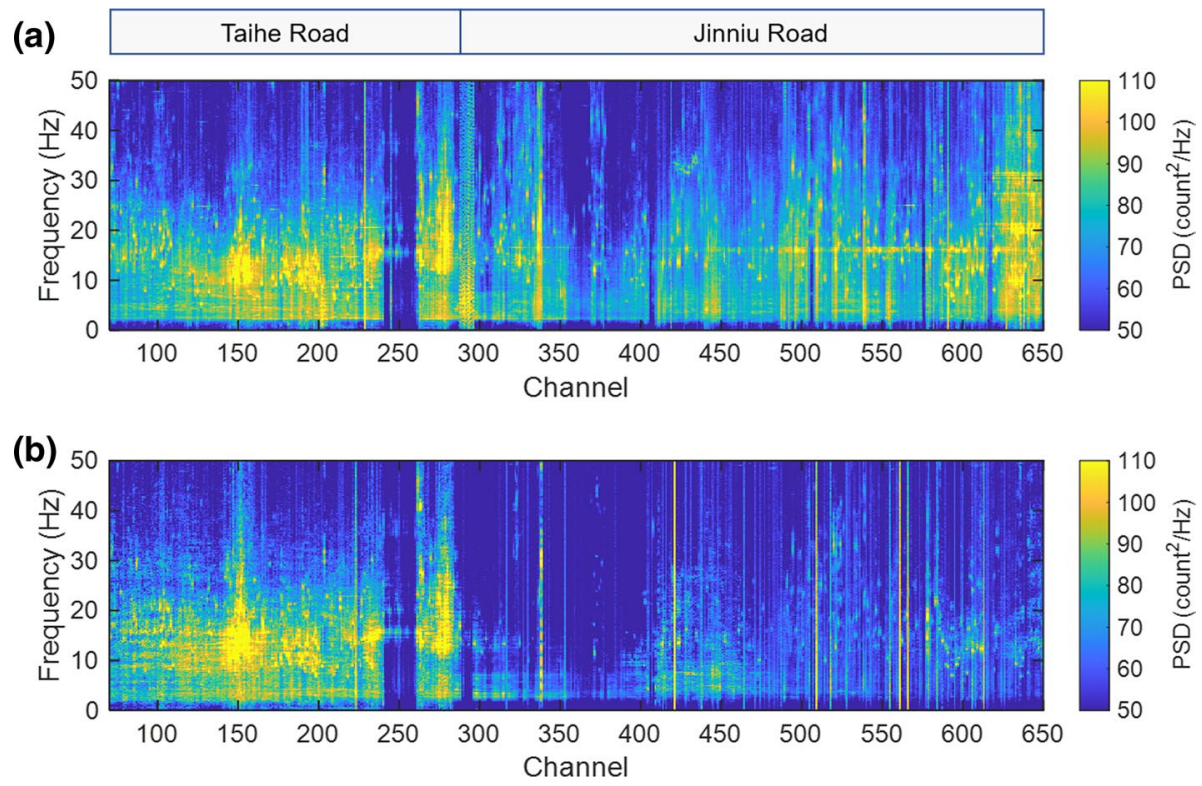

Fig. 3 a The power spectral density of the daytime ambient noise record. b Same as (a) but at night 


\subsection{NCF Computation and Classification}

The NCF between two stations can be used as the empirical Green's function (Shapiro et al. 2005). We referred to the procedure of computing NCFs by Zeng et al. (2017) as shown in Fig. 4a. Since the ambient noise is concentrated below $30 \mathrm{~Hz}$, we resampled it to $100 \mathrm{~Hz}$ to reduce the computational time cost. Continuous data were chopped into 30-s long segments and band-pass filtered to 1-30 Hz. Temporal normalization and spectral whitening were employed to reduce the interference of strong transient noise. Then the cross-correlation functions were computed with processed data of each segment and stacked with the time-frequency domain phase weighting stacking (tf-PWS, Schimmel and Gallart 2007; Zeng et al. 2016) to obtain the final NCF. To obtain an optimal stacking time span, NCFs of two channel-pairs with different time spans in both daytime (6:00-10:00 PM) and nighttime (0:00-4:00 AM) were computed (Fig. 5a-d). Rayleigh wave signal on NCFs clearer emerges with longer time span. SNR defined as the ratio of the maximum value of the surface wave window to the root mean square value of the coda wave window was adopted to demonstrate the convergence of NCF (Fig. 5e). After four hours of stacking, the NCFs of channel-pair in the Taihe Road in daytime and nighttime reach high SNR up to $20 \mathrm{~dB}$. For channel-pair in the Jinniu Road, SNR of four-hour NCFs in daytime is higher than that in nighttime. Since the four-hour NCFs of channel-pairs in both the Taihe Road and the Jinniu Road in the daytime are close to the 16-h NCFs (Fig. 5a, 5c), four-hour NCFs in daytime are used in this study.

Various signals on the NCFs are reported in previous studies and common offset or shot gathers were used to identify signals (e.g., Zeng et al. 2017; Williams et al. 2021). We
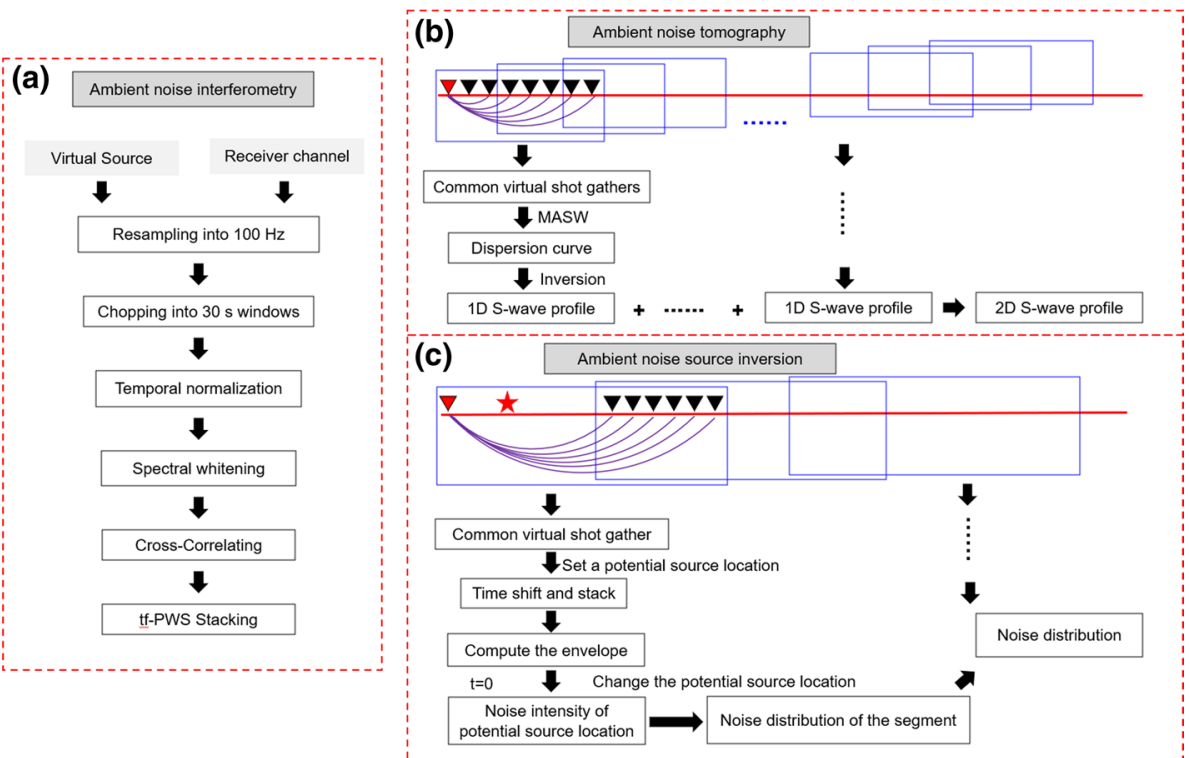

Fig. 4 a Procedure of noise cross-correlation function (NCF) computation in this study. b and $\mathbf{c}$ Procedures of ambient noise tomography and ambient noise source inversion. The red lines are the fiber-optic cable. The red and black triangles represent the virtual source and the receiving channels, respectively. The red star indicates the location of potential noise sources 
(a)

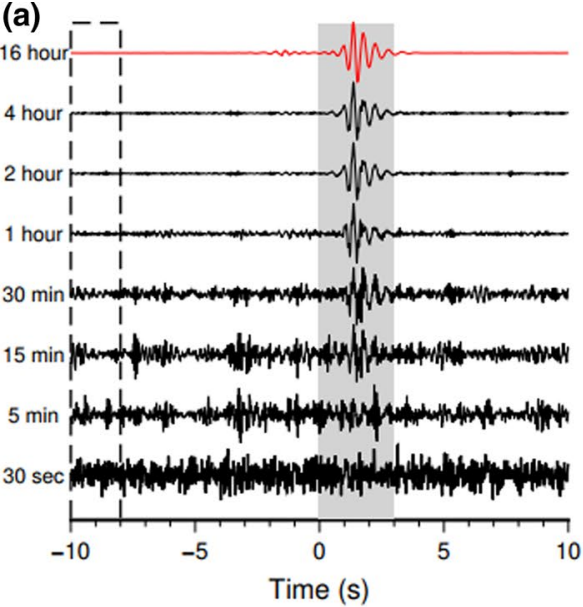

(c)

(c) ${ }_{16 \text { hour }}^{--}$

1 hour hour

1 hour r 30 min

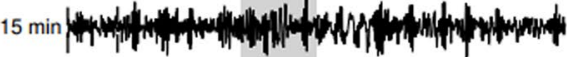
5 min

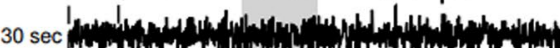

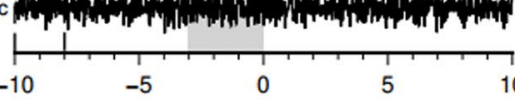

(e) (b)

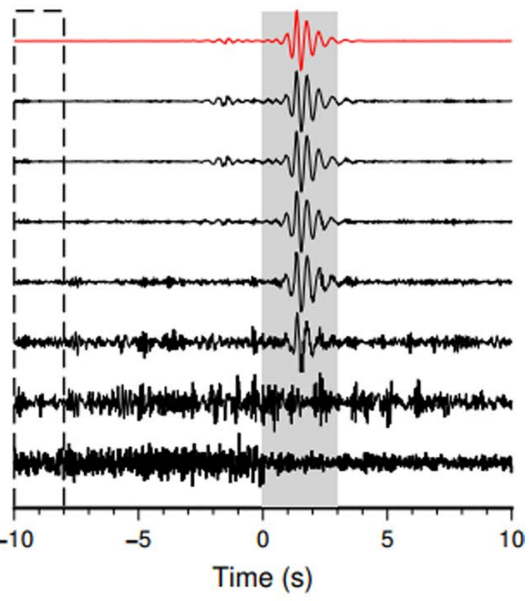

(d)

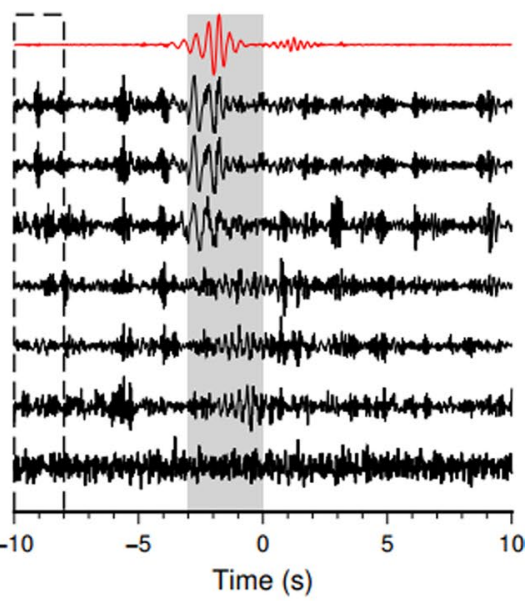

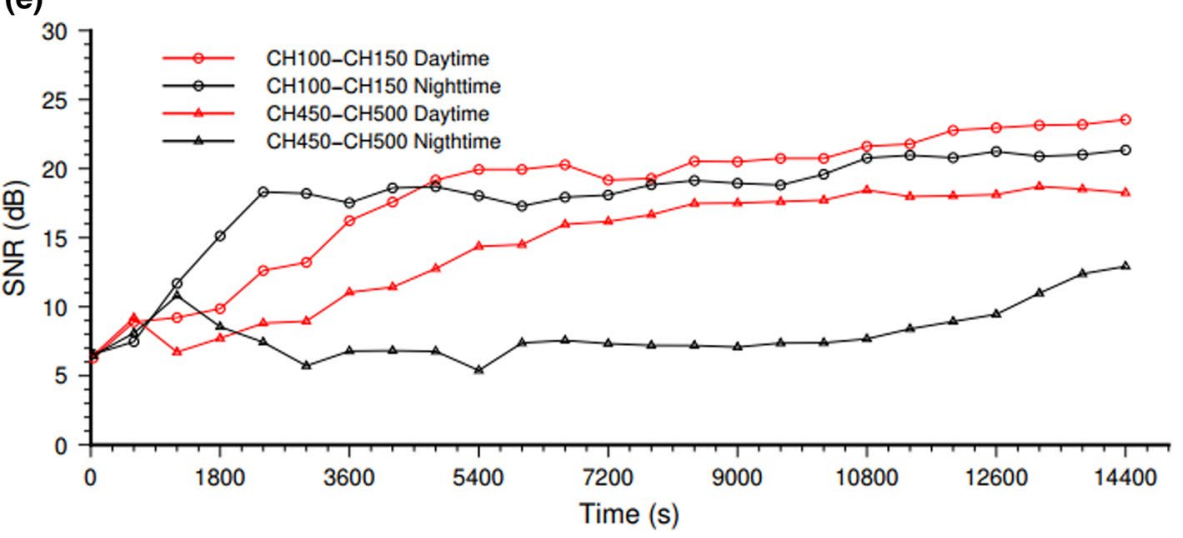

Fig. 5 a The NCF of CH100-CH150 in the Taihe Road of various time spans in daytime. The signal windows are highlighted by gray shade zones, whereas the noise windows are represented by dashed boxes. The NCFs computed with the whole 16-h data are shown in red. b Same as (a) but for nighttime. c Same as (b) but for CH450-CH500 in the Jinniu Road. d Same as (c) but for nighttime. e Is the SNR for (a) to (d) 
calculated the NCF by setting every two channels as a pair with an interval of $187 \mathrm{~m}(25$ channels) and shifted the 'channel pair' one by one till the end to obtain common offset gathers (COG). To reduce the impact of cable coupling, we stacked the NCFs of the adjacent five channel-pairs, and the COG is shown in Fig. 6. The COG can be divided into three categories. The first category includes CH70-CH220 in the Taihe Road, CH340-CH390 in the Jinniu Road, and CH560-CH570 in the Jinniu Road, which manifests as clear Rayleigh wave signals on the NCF. The Rayleigh wave signal emerges on the positive lag of NCFs of channel-pairs in the CH70-CH150 segment, which suggests most noise signal comes from the north side. The arrivals of Rayleigh wave show slight variation in this segment. For example, the velocity of $\mathrm{CH} 140-\mathrm{CH} 190$ is slightly lower than that of the two sides.

The second category is the remaining part of the Taihe Road (CH220-CH280), whose NCFs do not show clear surface wave signals because this section of the fiber-optic cable is twined and poorly coupled with the ground (Song et al. 2021). The third category is the majority of the Jinniu Road (CH300-CH340, CH390-CH560, and CH570-CH650), which is presented as complex NCFs. Strong precursor signal before the Rayleigh wave propagating between channel-pair is observed on the NCFs of CH390-CH560 and CH570-CH650, which indicates the existence of localized noise sources (e.g., Zeng et al. 2017; Williams et al. 2021). There are many intersections in this segment compared with Taihe Road, which may be related to the generation of precursor signals.

In summary, the first category NCFs include high-quality Rayleigh wave signals that can be used in ambient noise tomography, whereas precursor signals on the third category NCFs strongly affect surface wave dispersion measurement (Fig. 7) that can be used to invert for source distribution and the second category NCFs from twined segment data are discarded in this study.

\subsection{Ambient Noise Tomography}

Figure $4 \mathrm{~b}$ shows the procedure of ANT used in this study. MASW was employed to extract dispersion curve with common virtual-shot gather (Fig. 7a, 7b). The dispersion spectrum is calculated following Eq. 1, and the phase velocity was picked at the maximum stacking energy point of each frequency, while the uncertainty of picking was estimated by the zone with the $90 \%$ energy of the maximum (Fig. 7). An array length of 30 channels $(225 \mathrm{~m})$ and a minimum offset of 10 channels $(75 \mathrm{~m})$ were chosen to avoid far and near field effects (Park et al. 1999), respectively.

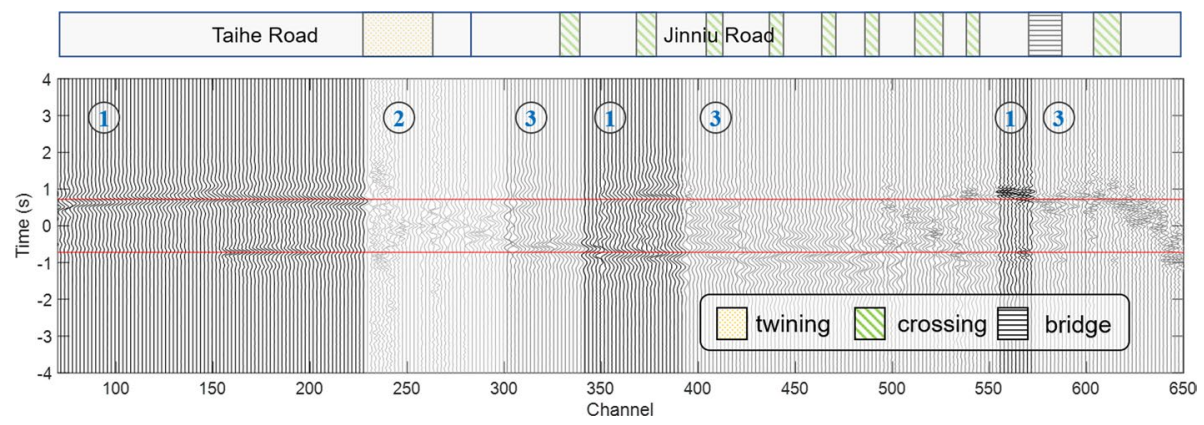

Fig. 6 The NCFs of the whole DAS array (comment offset gather), where the offset is equal to 25 channels. The red line represents the arrival at a velocity of $260 \mathrm{~m} / \mathrm{s}$. The number indicates classification 
(a)

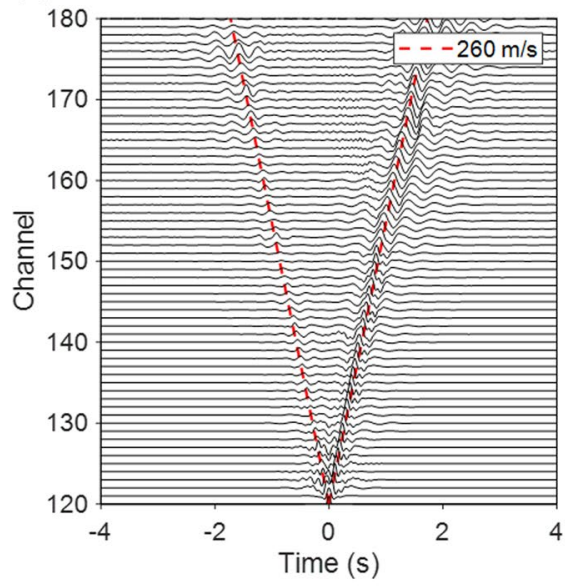

(c)

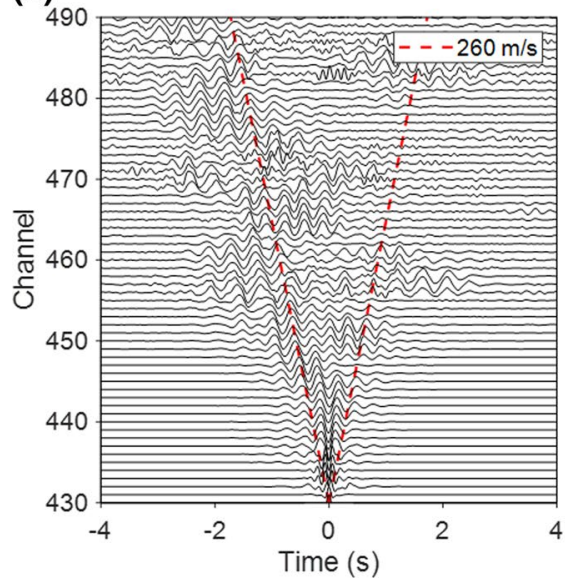

(b)

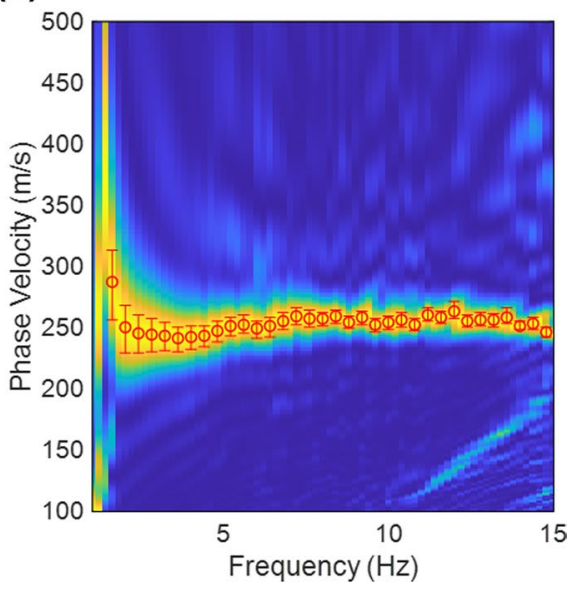

(d)

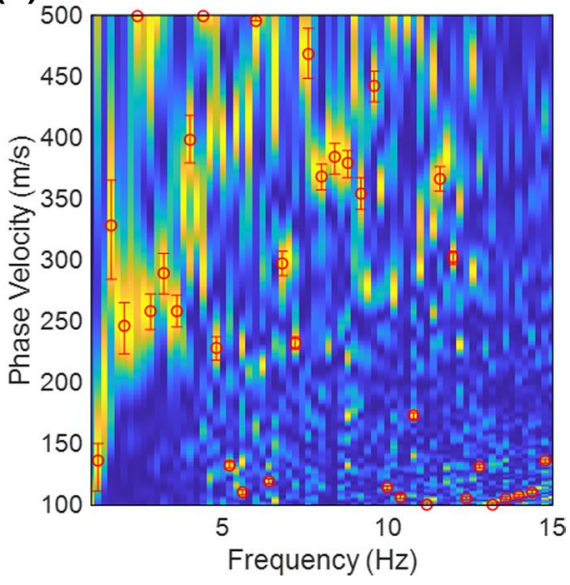

Fig. 7 Common virtual-shot gather (a) and dispersion spectra (b) in Taihe Road. The virtual source is CH120. $\mathbf{c}$ and $\mathbf{d}$ is same to $\mathbf{a}$ and $\mathbf{b}$ but in Jinniu Road. The virtual source is CH430. Red circle denotes the maximum point of each frequency. The picking uncertainty is shown in red bar, which is defined by the zone with $90 \%$ energy of the maximum energy of each frequency

$$
E(f, c)=\sum_{i=1}^{N} e^{i 2 \pi f x_{i} / c} \frac{U\left(x_{i}, f\right)}{\left|U\left(x_{i}, f\right)\right|}
$$

where $E(f, c)$ is the dispersion spectrum in frequency phase velocity domain. $x_{i}$ is the offset. $U\left(x_{i} f\right)$ is record of $i$-th channel in the frequency domain.

According to the dispersion spectrum (Fig. 7b), the maximum wavelength of the surface wave signal is approximately $300 \mathrm{~m}$ in Taihe Road. The maximum depth of the dispersion curve inversion constraint is about the half of the maximum wavelength (Rix and Leipski 1991). But in practice, it is often smaller than half of the wavelength. Therefore, we only inverted for the shallow $100 \mathrm{~m}$ structure. The model consists of five layers, including two 
20-m thick layers, two 30-m thick layers, and a half-space. Since the phase velocity of Rayleigh wave is more sensitive to $\mathrm{S}$-wave velocity, the P-wave velocity is not independently inverted and a fixed $\mathrm{Vp} / \mathrm{Vs}$ ratio (1.73) is adopted, whereas the density was also set as $2.0 \mathrm{~g} /$ $\mathrm{cm}^{3}$. The forward modeling of phase velocity was conducted with the Computer Programs for Seismology (Herrmann 2013) with layered model.

The neighborhood algorithm (Sambridge 1999a, 1999b), which can effectively avoid the global minimum and obtain the global optimal solution, was used for the inversion. To reduce the multiplicity of solutions and velocity contrast, we applied first-order Tikhonov regularization to objective function (Eq. 2).

$$
\varnothing_{m}=\left\|d^{p r e}-d^{o b s}\right\|_{2}^{2}+\alpha^{2}\|L m\|_{2}^{2}
$$

where $\varnothing_{m}$ is the objective function, $d^{p r e}$ is the theoretical dispersion curve, $d^{o b s}$ is the observed one, $L$ is the first-order Tikhonov regularization matrix, $m$ is the velocity model, and $\alpha$ is the damping factor ( 0.1 is used in this paper).

The initial models including 50 sampling models were generated uniformly in parameter space. The 25 models with the lowest misfit were kept as chosen model. New 25 models were randomly generated within the Voronoi cells of the 25 chosen models for the next iteration. After 200 iterations, the model with the minimum misfit was the final result. The 2D profile is obtained by assembling the 1D layered models.

\subsection{Ambient Noise Source Inversion}

For the third category, the NCF is relatively complex, and it is difficult to extract an accurate dispersion curve for the shallow structure (Fig. 7c, 7d). Retailleau et al. (2021) proposed a method to determine the intensity of ambient noise among linear array according to the NCFs (Fig. 4c). First, one channel was chosen as the virtual source to calculate the NCFs with other channels. Then, we assume the location of a potential noise source inside the linear station line, and shifted each NCF by the difference between the propagation time from the potential noise source to the receiver channels and from the potential noise source to the virtual source. The envelope was computed after the time-shifted stacking of the NCFs. The ambient noise intensity at the location is the amplitude at $t=0$. By changing the location of the potential source, the ambient noise distribution along the linear array was obtained.

An example is shown in Fig. 8, and the virtual source is located in $\mathrm{CH} 400$. We assume that the two potential noise sources are located at $\mathrm{CH} 400$ and $\mathrm{CH} 450$, respectively. Time shifts were estimated based on the apparent velocity of approximately $220 \mathrm{~m} / \mathrm{s}$. Since too long windows are not necessary in this frequency, the NCF of 4-s time windows centered at the time shifts were selected (Fig. 8a, 8b). We aligned the NCF in the windows and stacked, then calculated the envelope, and the intensity of ambient noise (the amplitude where $t=0$ ) at the two locations were obtained (Fig. 8c, 8d). When the location of the potential noise source is close to the virtual source or receiver channels, the calculated energy is affected by the direct surface wave and is not exactly the intensity of this location, so we discard it (e.g., shaded part in Fig. 8c). 
(a)

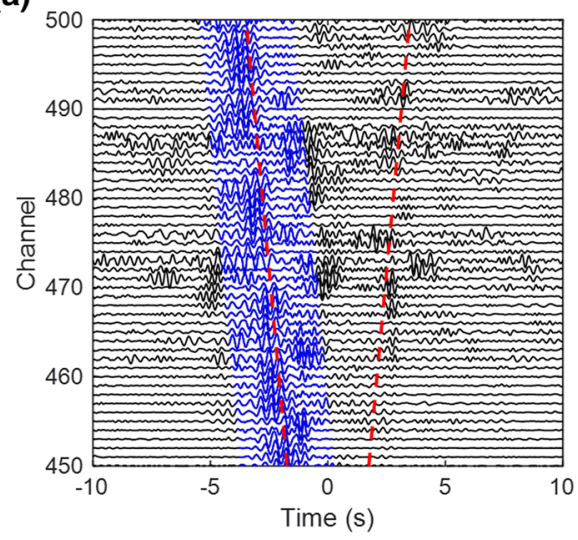

(c)

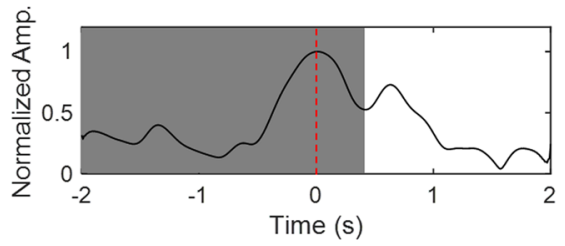

(b)

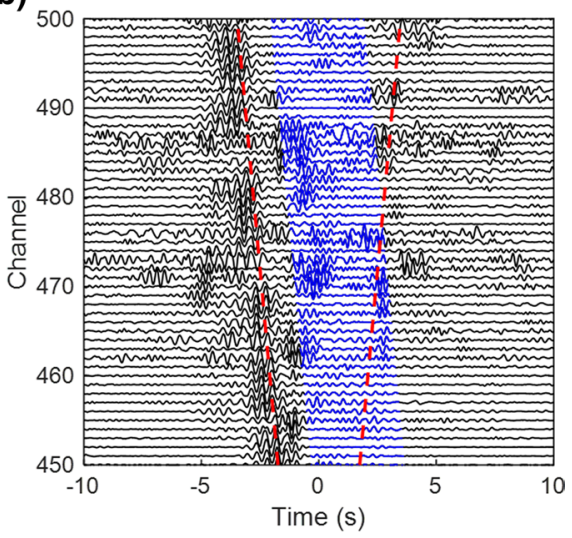

(d)

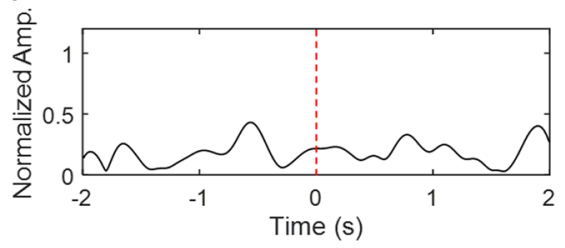

Fig. 8 a The common virtual-shot gather of $\mathrm{CH} 450-\mathrm{CH} 500$, where $\mathrm{CH} 400$ is the virtual source. The red line indicates the arrival predicted with a velocity of $220 \mathrm{~m} / \mathrm{s}$. The blue waveforms denote the stacking window of the selected surface wave signal where the potential noise source is located at CH400. b Same as (a) but the potential noise source is located at $\mathrm{CH} 450$. c and $\mathbf{d}$ The envelope calculated after the timeshifted stacking from $\mathbf{a}$ and $\mathbf{b}$, respectively. The shaded area is affected by the direct surface wave and is discarded. The red line represents the ambient noise intensity

\section{Results}

\subsection{Shallow Structure Beneath the Taihe Road}

Since the first category in Jinniu Road is too short to construct a 2D profile, only the shallow structure beneath Taihe Road was computed. CH60-CH230 was divided into 28 segments and each segment used in MASW computation consists of 30 channels while the overlap between two consecutive segments is 25 -channel long (Fig. 4b). Dispersion curves of 28 segments were obtained for imaging the shallow structure beneath the Taihe Road (Fig. 9a). The frequency range of most dispersion curves is about $1-7 \mathrm{~Hz}$ (Fig. 9a). The minimum wavelength is about $40 \mathrm{~m}$ that is sensitivity to the structure of shallow $20 \mathrm{~m}$, whereas the maximum wavelength is about $300 \mathrm{~m}$ and sensitive to $150 \mathrm{~m}$ deep structure. Strong variation is observed that phase velocities in the north part (CH145-CH195) is much lower than ones in the south part (Fig. 9a).

The 28 dispersion curves were inverted for the 1D layered models that were used to assemble into the final 2D profile beneath the Taihe Road (Fig. 9b). Figure 10 shows dispersion curve fitting of two typical segments in the south and north parts. The velocity structure beneath Taihe Road is in the range of 200-400 m/s. Since the thickness of the sedimentary layer in this area is about $500 \mathrm{~m}$ (Sun et al. 2019) which exceeds the maximum 

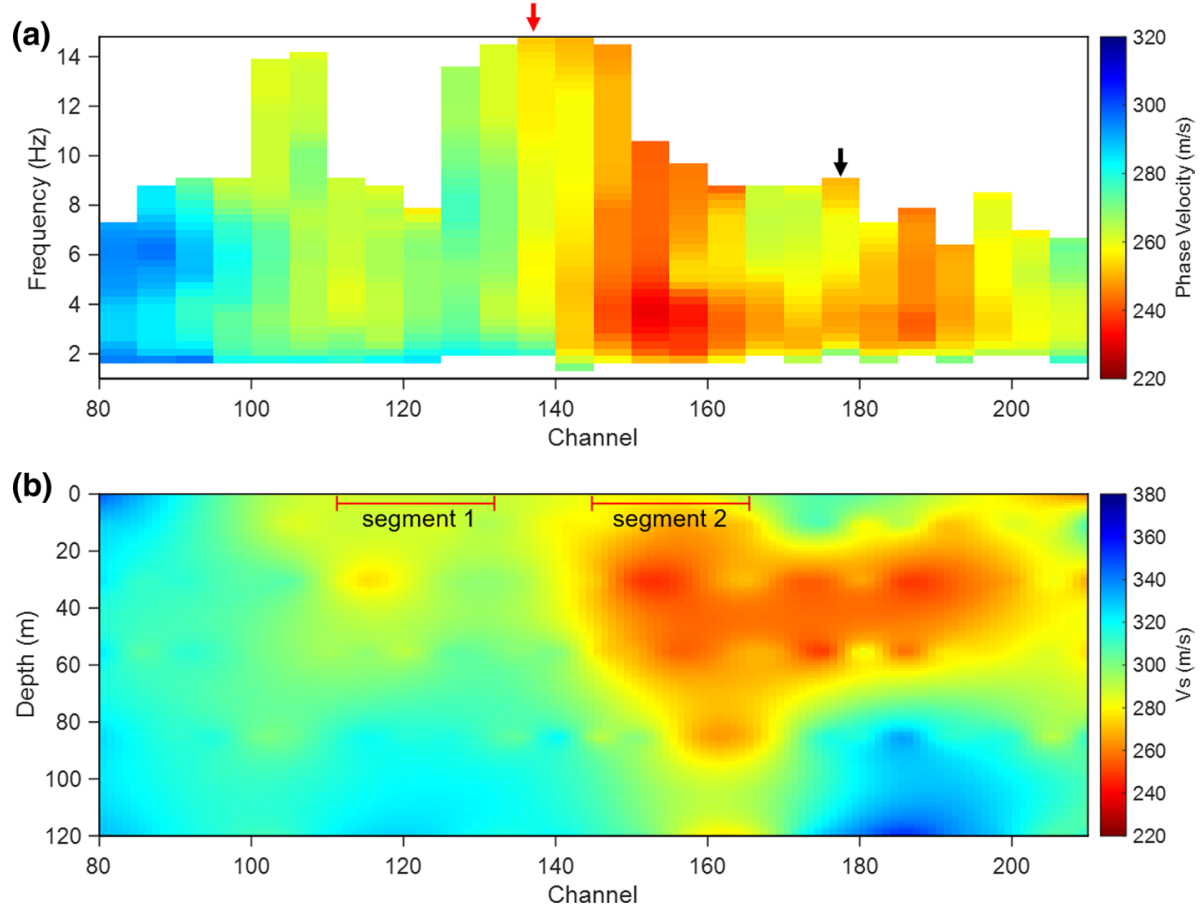

Fig. 9 a The dispersion curve of segments along the Taihe Road. The red and black arrows indicate the position of the dispersion curve in Fig. 10. b The S-wave velocity profile along the Taihe Road. The black bars are the position of geophone arrays

(a)

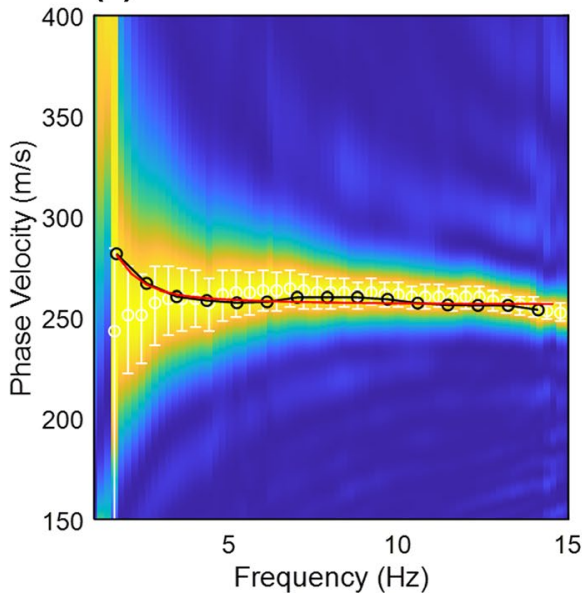

(b)

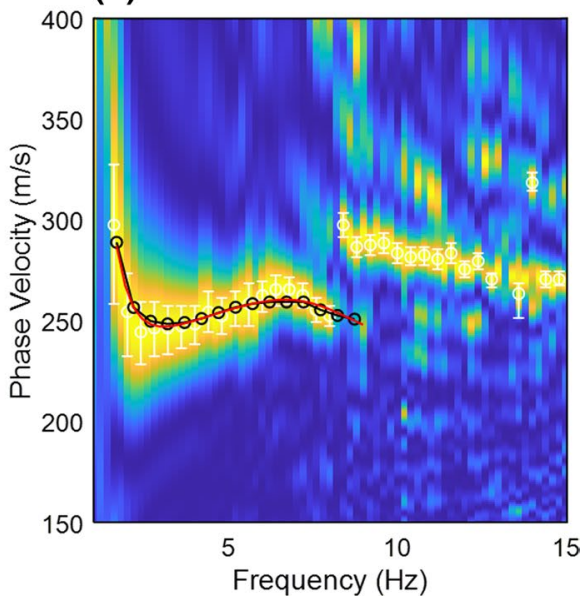

Fig. 10 a The dispersion curve fitting of $\mathrm{CH} 125-\mathrm{CH} 155$ segment (red arrows in Fig. 9a). The black line represents the observed one and the red line represents the one predicted by the inverted model. $\mathbf{b}$ is same as (a) but for CH165-CH195 (black arrows in Fig. 9a). The picking uncertainty is shown in white bar 
depth of our inversion model, such sharp discontinuity across the sediment and bedrock is not observed in our result (Fig. 9b). A low-velocity zone down to 80-m deep was imaged in the north part (CH145-CH195), which is consistent with the dispersion measurement shown in Fig. 9a. There is a pond to the northeast of the CH140-CH200 segment (Fig. 1) that may be related to this low-velocity zone.

The inversion result was affected by the picking uncertainty, so recovery tests were utilized to evaluate this effect. The true models are extracted from our final models beneath the $\mathrm{CH} 140$ and $\mathrm{CH} 180$. The first one is a gradient model, whereas the latter one includes a lower velocity layer (Fig. 11). The input data were obtained from adding Gaussian noise into theoretical dispersion curves of two true models. When the picking uncertainty is $10 \%$, the top four layers can still be recovered well in both two models, but velocity of the halfspace changed greatly. However, the picking uncertainty rarely reaches $10 \%$ in this study.

Besides the recovery tests, other observations also support our model. The heavy truck moving along the Taihe Road excited clear signals that were well recorded by the DAS array (Fig. 12a). The average spectra of all channels suggest that the dominant frequency is $2.4 \mathrm{~Hz}$ (Fig. 12c). Therefore, records are shifted with a velocity of $260 \mathrm{~m} / \mathrm{s}$ that is close to the average phase velocity at $2.4 \mathrm{~Hz}$. Two discontinuities emerge on the shifted records around $\mathrm{CH} 145$ and $\mathrm{CH} 165$ (Fig. 12b), which were used to divide the array into three segments with different apparent velocities. The average velocity in each segment

(a)

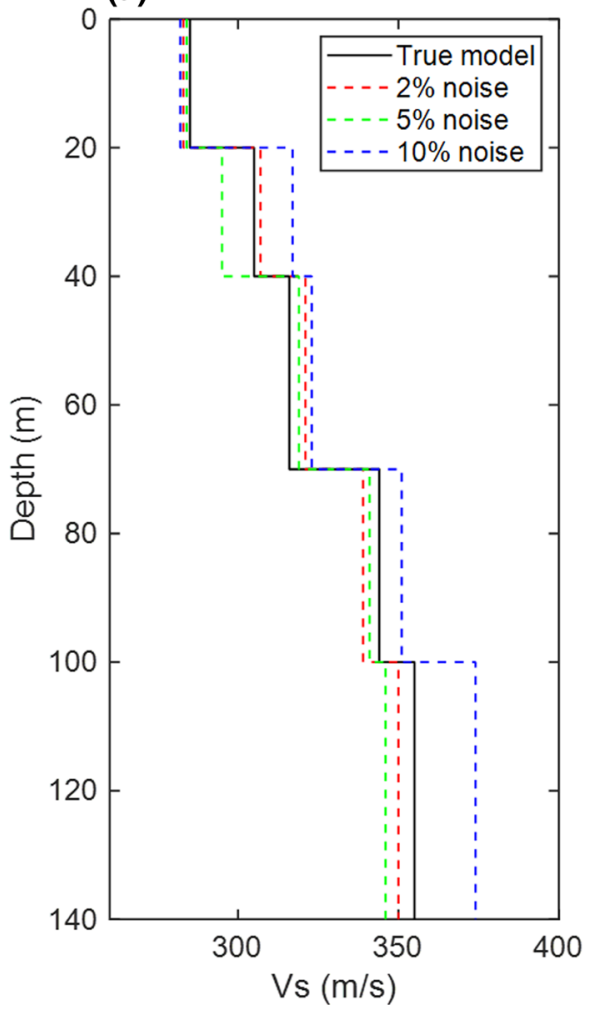

(b)

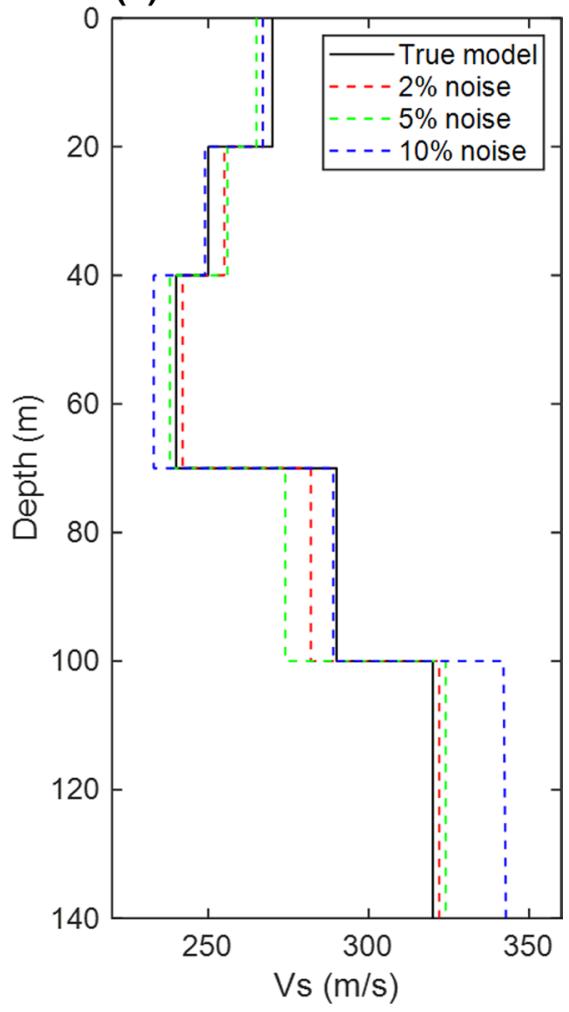

Fig. 11 Recovery test. a Gradient model. b Low-velocity layer model 
(a)

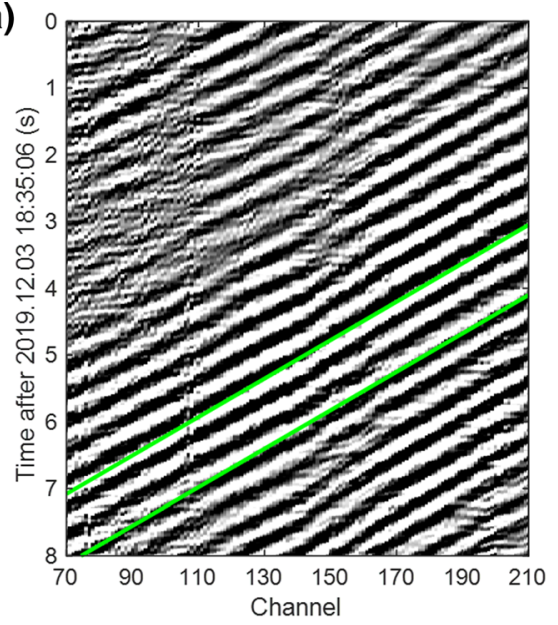

(c)

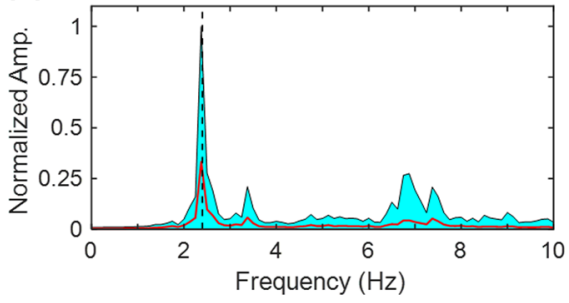

(b)

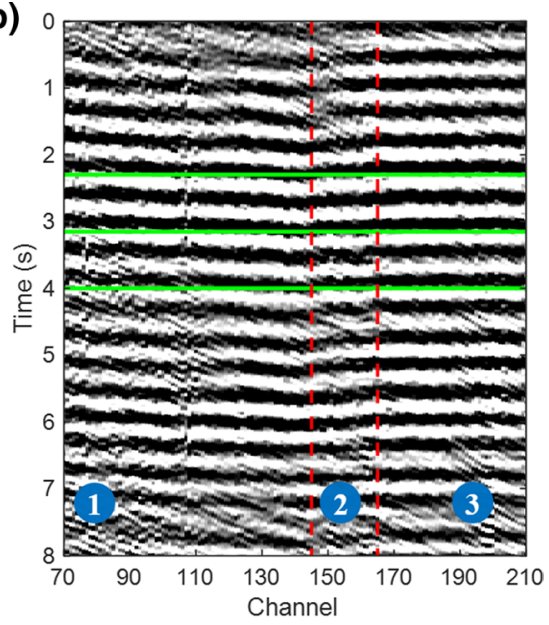

(d)

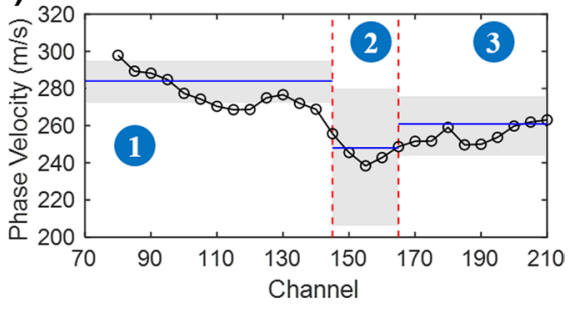

Fig. 12 a The seismic signal excited by a vehicle moving along the Taihe Road recorded by DAS. The green lines represent the arrivals predicted with a velocity of $260 \mathrm{~m} / \mathrm{s}$. b The signal shown in a corrected with a $260 \mathrm{~m} / \mathrm{s}$ velocity. The red dashed lines denote boundaries among three zones. c Spectrum of the traffic signal shown in a. The red line is the average spectrum of all channels and the cyan shaded zone indicate the $95 \%$ confidence level. The black dash line represents the dominate frequency $2.4 \mathrm{~Hz}$. d Comparison of model predicted and observed phase velocities at $2.4 \mathrm{~Hz}$. The black line with open circles shows theoretical phase velocities of $2.4 \mathrm{~Hz}$ predicted by the velocity models shown in Fig. 9b, whereas the blue line is the $2.4 \mathrm{~Hz}$ phase velocities obtained from the vehicle signals in three zones. The shaded zone denotes the uncertainties of observed phase velocities, which is defined by the zone with $90 \%$ energy of the maximum energy of each frequency

was estimated with the MASW method. The results agree well with the phase velocity at $2.4 \mathrm{~Hz}$ predicted by our model (Fig. 12d).

Two linear geophone arrays were deployed along the Taihe Road in CH110-CH132 and $\mathrm{CH} 150-\mathrm{CH} 172$ segments (Fig. 9b). Each array consists of 18 short-period geophones with a spacing of $10-\mathrm{m}$. A similar procedure was adopted to process geophone data and build layered model. The dispersion spectra of two datasets are similar and the difference between south and north parts is confirmed in the geophone results too (Fig. 13). The general patterns of inverted layered models are also consistent with each other (Table 1).

\subsection{Traffic Noise Distribution of the Jinniu Road}

The NCFs of channel-pairs in the Jinniu Road are complex, and they are difficult to extract accurate dispersion information for imaging (Fig. 7). There are many road crossings in 
(a)

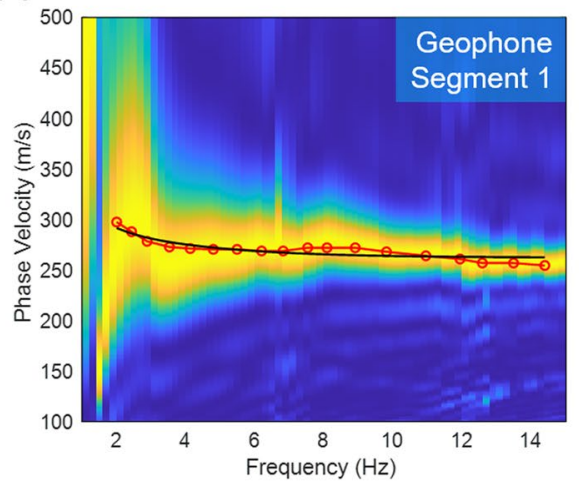

(c)

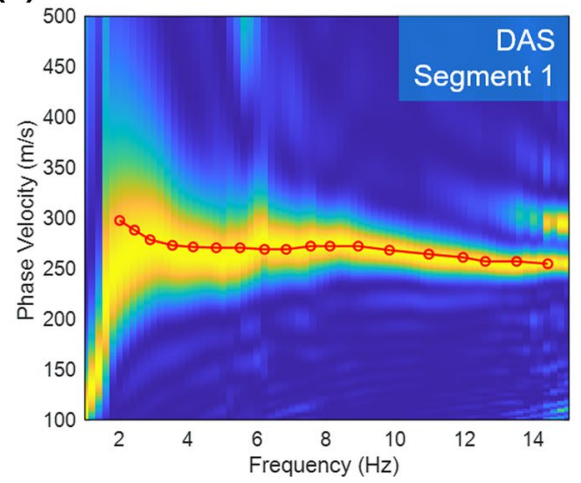

(b)

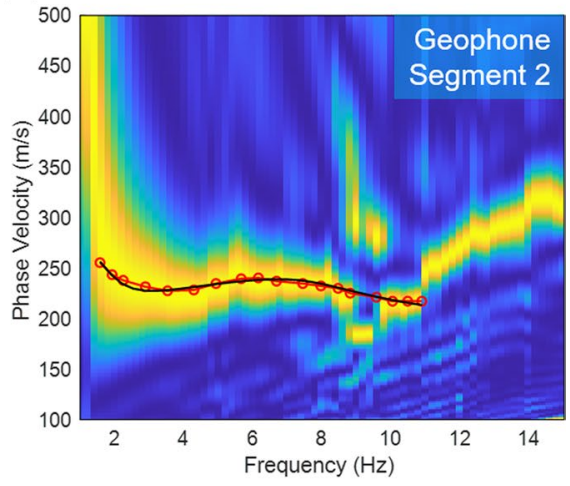

(d)

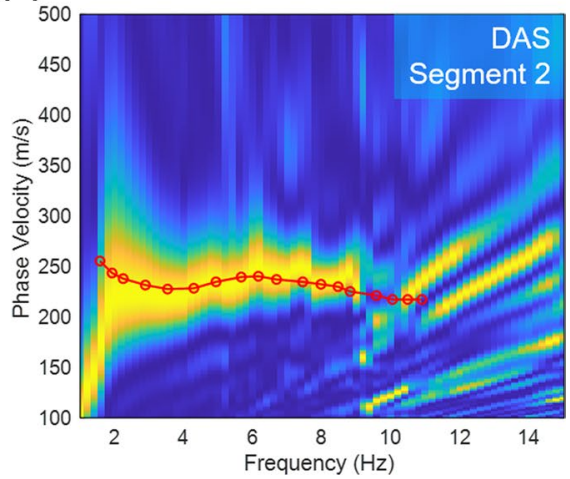

Fig. 13 a Dispersion spectrum obtained from the geophone array deployed along the segment 1 in Fig. $9 \mathrm{~b}$. b Same as a but for segment 2 in Fig. 9b. c The dispersion spectrum calculated by DAS data of segment 1 . $\mathbf{d}$ Same as $\mathbf{c}$ but for segment 2 . The red line in $\mathbf{a}$ and $\mathbf{c}$ is the dispersion curve extracted from $\mathbf{a}$. The red line of $\mathbf{b}$ and $\mathbf{d}$ is extracted from $\mathbf{b}$. The black lines in $\mathbf{a}$ and $\mathbf{b}$ are the theoretical dispersion curves for inversion model, respectively

Table 1 The inversion result of the dispersion curve extracted from the geophones and DAS data

\begin{tabular}{llllllll}
\hline Layer number & Thickness & \multicolumn{2}{l}{ Vs of segment1 $(\mathrm{m} / \mathrm{s})$} & & \multicolumn{2}{l}{ Vs of segment2 (m/s) } & Search range $(\mathrm{m} / \mathrm{s})$ \\
& & Geophone & DAS & & Geophone & DAS & \\
\hline 1 & $20 \mathrm{~m}$ & 285 & 288 & & 246 & 265 & {$[200,300]$} \\
2 & $20 \mathrm{~m}$ & 305 & 287 & 263 & 250 & {$[200,350]$} \\
3 & $30 \mathrm{~m}$ & 316 & 294 & 257 & 268 & {$[200,400]$} \\
4 & $30 \mathrm{~m}$ & 344 & 311 & 293 & 299 & {$[200,500]$} \\
5 & - & 355 & 324 & & 310 & 315 & {$[200,500]$} \\
\hline
\end{tabular}

Jinniu Road, so we hypothesized that the complex traffic activity leads to precursor signals and coda waves. Numerical simulation was utilized to investigate the source distribution effect on NCF. 
Lindsey et al. (2020) suggests that moving vehicle generates two signals including the pseudo-static deformation at low-frequency band $(<1 \mathrm{~Hz})$ and surface wave signal between 1 and $30 \mathrm{~Hz}$. Vertical single force is a good approximation of the surface wave source in this case (Brenguier et al. 2019; Jousset et al. 2018). Here we used the frequency-wavenumber method (FK, Ben-Zion and Zhu 2002) to compute synthetic displacement seismograms that were differenced to final strain seismogram. To simulate random noise, multiple sources were used and the origin time was set as random number. Since the Doppler effect of vehicle movement has little influence on the NCF (Yan et al. 2021), no additional process was considered for this issue.

(a)

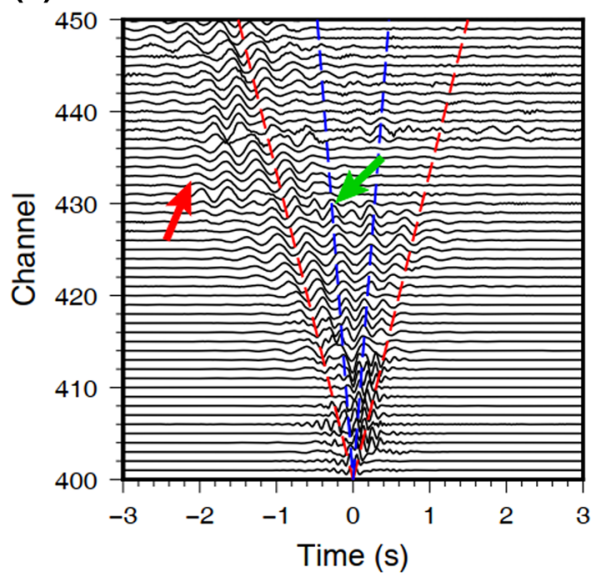

(c)

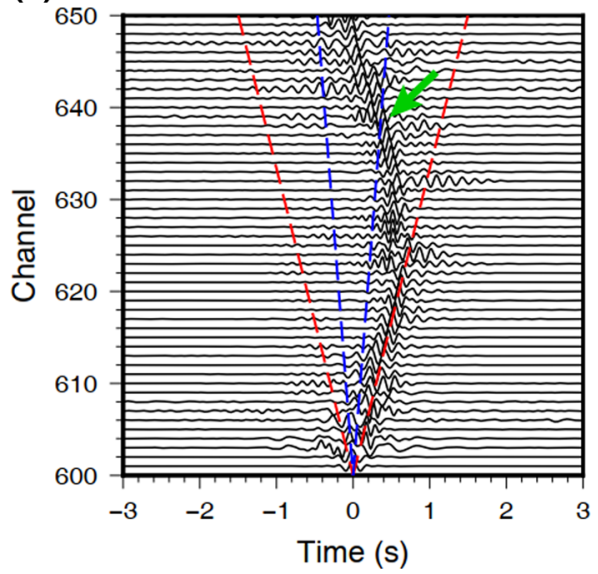

(b)

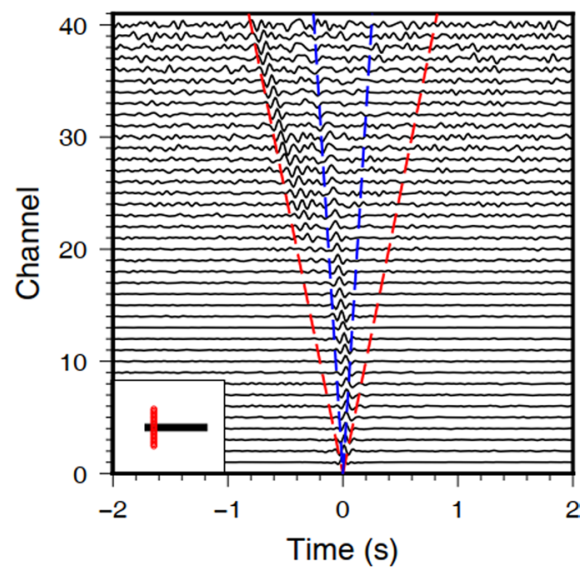

(d)

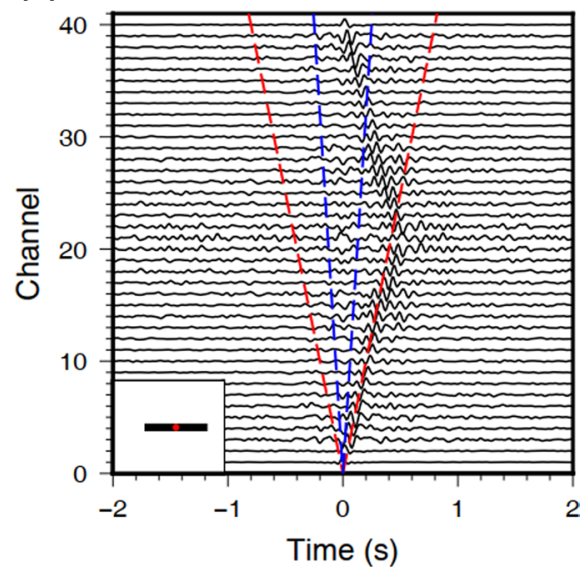

Fig. 14 Synthetic tests of two noise source distribution cases. a The record section of $\mathrm{CH} 400-\mathrm{CH} 450$ at Jinniu Road. The red and green arrows indicate the long coda wave and the precursor signal, respectively. b A synthetic record section with the noise sources perpendicular to the optical cable. c The record section of CH600-CH650 at Jinniu Road. d A synthetic record section where the noise source is located in the DAS array. The red and blue dashed lines represent the velocity of $250 \mathrm{~m} / \mathrm{s}$ and $800 \mathrm{~m} / \mathrm{s}$, respectively. The channel spacing is $5 \mathrm{~m}$ for synthetic tests 
Figure 14 shows observed and synthetic common virtual-shot gathers of two segments. Figure 14a is the common virtual-shot gather of $\mathrm{CH} 400-\mathrm{CH} 450$, and $\mathrm{CH} 400$ is the virtual source, showing the precursor signal and long coda wave-train. This case can be explained by a distribution of ambient noise perpendicular to the optical cable, and no noise along the direction of the cable was added (Fig. 14b). The station farthest to the left was used as the virtual source to calculate the NCF. The vehicles traveling perpendicular between the arrays reduce the travel time difference between the noise source to the virtual source and the receiving channel, which generates the precursor signal before the direct surface wave in NCF record section (Fig. 14b). There are intersections on Jinniu Road with an interval of approximately $200 \mathrm{~m}$, which affects the surface wave emerge on the NCFs. The second case is a localized noise source case shown in Fig. 14c, which is the common virtual-shot gather of the $\mathrm{CH600-CH650} \mathrm{segment} \mathrm{with} \mathrm{the} \mathrm{virtual} \mathrm{source} \mathrm{is} \mathrm{CH} 600$. Clear precursor signal on NCF suggests a localized noise source. According to the records, it is estimated that the location of the noise source is approximately CH625, but there is no intersection nearby. The construction in this area or the uneven road surface may explain the strong noise source distribution, which is also the reason for the high energy of the PSD of the noise in the daytime along this section of Jinniu Road (Fig. 3).

As discussed above, a complex distribution of noise sources in the urban environment is caused by the influences of intersections and local human activities or road conditions. The method proposed by Retailleau et al. (2021) was employed to obtain noise intensity along the Jinniu Road. CH400-CH580 was divided into three segments and each segment used in ambient noise inverse consists of 100 channels while the overlap is 60 channels. The noise intensity distribution along the Jinniu Road was obtained and normalized with the intensity of direct wave (Fig. 15). The intensity of noise sources near three intersections increased significantly (CH410, CH440, and CH520, whereas two intersections (CH468 and CH490) did not due to the lower traffic flow. Some strong signals between intersections may be

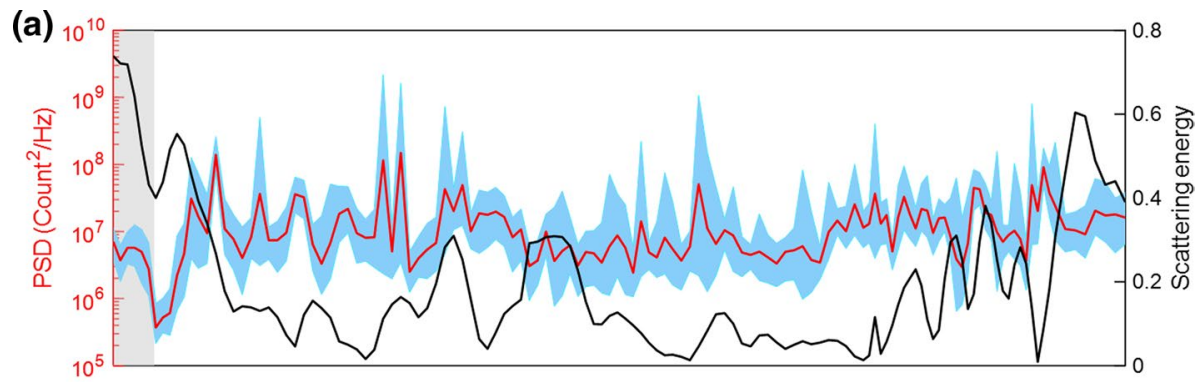

(b)

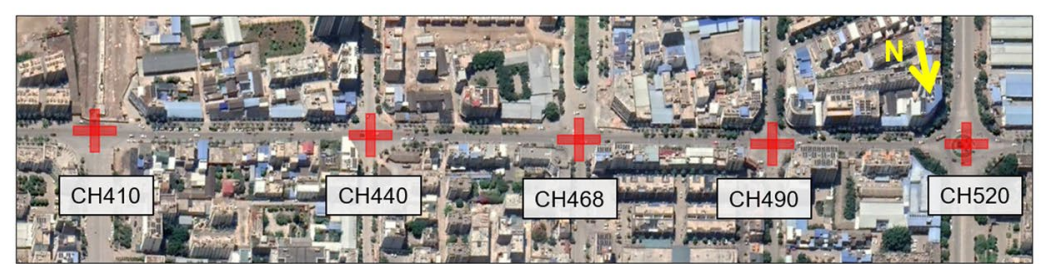

Fig. 15 a The noise source intensity along the Jinniu Road (black line) and PSD along Jinniu Road. The red line is the average of 10-min PSDs and the blue shaded zone indicates the upper and lower bounds during $4 \mathrm{~h}$. The gray shaded area is a discarded area. b The satellite photo of Jinniu Road. The red crosses denote the crossings 
caused by the uneven road surface (CH440-CH460 and CH490-CH510). 4-h continuous data were chopped into 10-min segments, and the PSD of each segment was calculated and summed in 1-30 Hz (Fig. 15), and the result is consistent with the distribution of ambient noise sources computed by NCFs. However, the intensity of the intersection is weaker than on both sides, which was affected by the coupling of the fiber-optic cable. In the case of good coupling, the noise source intensity can be estimated according to PSD, whereas for existing urban fiber-optic cables, the result obtained by the NCF is more representative. In addition, PSD indicates the noise intensity near a single channel, while the NCFs reflect the coherent influence. Compared with the intensity of single-channel noise, it is easier to judge the influence of the noise signal at a certain location on ANT based on the calculation of the NCF.

\section{Discussion}

Due to the importance of the Binchuan Basin area, the China Earthquake Administration has deployed 381 short-period three-component seismometers in this region over an area of $40 \times 40 \mathrm{~km}$ with an average interval of approximately $2 \mathrm{~km}$. Zhang et al. (2020a) used earthquake travel time information to construct the velocity model of this region. The $\mathrm{P}$-wave velocity of the shallowest $3 \mathrm{~km}$ is approximately $4.6 \mathrm{~km} / \mathrm{s}$, and the $\mathrm{V}_{\mathrm{P}} / \mathrm{V}_{\mathrm{S}}$ ratio is 1.72. Due to the near-vertical incidence of rays in the shallow layer, the resolution of the shallow structure is limited. She (2021) used this dense array to calculate the NCF and extract the surface wave group velocity dispersion curve, improving the resolution of $\mathrm{S}$-wave imaging. However, the constraint of long-period signals on the shallow layer is weak. The results show that the S-wave velocity of the shallow layer at $100 \mathrm{~m}$ is approximately $2.5 \mathrm{~km} / \mathrm{s}$, which is much higher than that of the sedimentary cover (Liu et al. 2011). The HVSR method is sensitive to interface information and can be used to estimate the sediment thickness. Sun et al. (2019) used the HVSR method to determine that the thickness of the sedimentary cover in this area is approximately 500-600 $\mathrm{m}$ and that the average $\mathrm{S}$-wave velocity is approximately $500 \mathrm{~m} / \mathrm{s}$. Generally, the seismic velocity in the sedimentary cover increases with depth. In this paper, the velocity of the S-wave at $100 \mathrm{~m}$ below Taihe Road is approximately $200-400 \mathrm{~m} / \mathrm{s}$, which is in good agreement with the results of Sun et al. (2019). Limited by the station spacing, the horizontal resolutions of the models by Zhang et al. (2020a) and She (2021) are $5 \mathrm{~km}$ and $10 \mathrm{~km}$, respectively. In this paper, the horizontal grid spacing is about $40 \mathrm{~m}$, and low-velocity anomalies are identified at the hundred-meter scale, showing extremely high lateral resolution. Shallow velocity structure imaging depends on high-frequency signals, and dense observations can obtain accurate high-frequency information. The combination of DAS and telecommunication fiber-optic cables can improve the resolution of shallow imaging and supplement conventional observations. However, the application of DAS in the low-frequency band is still relatively rare (e.g., Shragge et al. 2019), and the observation of longer-period signals is still a challenge.

There are obvious precursor signals in the NCF of Jinniu Road (Fig. 14a), which makes it difficult to extract accurate dispersion curves. Tests show that these precursors are related to vehicles moving perpendicular to the optical cable at the intersection. The use of seismometers in urban environments is also affected by the uneven distribution of noise. The influence of the noise source distribution on imaging results can be reduced by artificially creating the vehicle distribution (e.g., Halliday et al. 2008) or by using active seismic sources such as the vibroseis (Song et al. 2018) and SOV (Dou 
et al. 2016). NCF denoising can also be used to reduce the influence of the noise source distribution (e.g., Cheng et al. 2018; Zhang et al. 2020b; Qiu et al. 2020). In addition, inverting the distribution and structure of noise sources can effectively avoid the influence of the uneven distribution of noise sources and obtain information on the source and structure simultaneously (Lehujeur et al. 2016).

Ambient noise tomography depends on the distribution of ambient noise sources. Retailleau et al. (2021) discussed and analyzed the uneven distribution of noise sources. McNamara and Buland (2004) discussed the intensity, frequency, and seasonal variation of ambient noise in the continental United States. High-frequency noise sources in the urban environment are distributed along roads, and the intensity is affected by the sizes of vehicles, the magnitudes of traffic flows, and the damage to the road surface. DAS can record the signals excited by vehicles and estimate the vehicle flow along the road utilizing statistics or machine learning (Martin et al. 2018; Lindsey et al. 2020). In this paper, the NCF of a linear array of stations can be used to estimate the relative distribution of the noise intensity along the whole road segment, which can be used to determine the traffic flow along the road perpendicular to the direction of the fiber-optic cable layout. The pressure on the road surface due to vehicles driving over the cable is the comprehensive effect of the vehicle's weight and tire contact with the ground (Yan et al. 2021). The intensity of the noise source distribution can estimate the damage of the road surface and provide guidance for urban road construction. Understanding the distribution of noise sources can further help to reconstruct the velocity structure below cities.

\section{Conclusions}

We use a 5.2-km long fiber-optic internet cable to perform traffic noise signal observations in an urban area. We use the ambient noise tomography method to calculate the NCFs of the 4-h continuous ambient noise signals recorded by the urban fiber-optic cable, and revealed the shallow $(100 \mathrm{~m}) \mathrm{S}$-wave velocity structure beneath Taihe Road. The theoretical phase velocity predicted by our model is in good agreement with the velocity of the surface wave signal excited by vehicles. The dispersion curve extracted by the short-period geophone array verifies the existence of the low-velocity zone. Through a synthetic test, we show that the distribution of ambient noise sources affects the calculation of the NCFs, and it is difficult to extract an accurate dispersion curve in the Jinniu Road. We estimate the noise distribution along Jinniu Road by using the NCFs of linear distributed stations, which revealed the traffic activities on urban roads. The distribution of ambient noise is in good agreement with the PSD recorded by collocated fiber-optic cables and shows the advantage of being less affected by coupling. With the distribution of effective ambient noise sources determined, ambient noise can be processed in a targeted manner to better serve the construction of shallow velocity structures. The urban optical cable is mainly laid along the road, and the traffic signal is the main noise signal in the cities. The combination of DAS with the existing fiber-optic cable has the advantages of a low cost, a high density, and the ability to acquire long-term, real-time observations and can both determine the traffic activities and image the velocity structure below the city with a high resolution. Surface wave signals emerge on NCFs in urban areas in a short period, which can provide frequent snapshots of the near surface across an urban area and monitor urban activities change. 
Acknowledgements This work was supported by the National Natural Science Foundation of China under grant No. 41974067. Authors appreciate helps from China Mobile Binchuan Company, Earthquake Agency of Yunnan Province, and Fotech Solutions Inc.

\section{References}

Ajo-Franklin JB, Dou S, Lindsey NJ, Monga I, Tracy C, Robertson M, Li X (2019) Distributed acoustic sensing using dark fiber for near-surface characterization and broadband seismic event detection. Sci Rep 9(1):1-14

Azwin IN, Saad R, Nordiana M (2013) Applying the seismic refraction tomography for site characterization. APCBEE Proc 5:227-231

Bao F, Li Z, Yuen DA, Zhao J, Ren J, Tian B, Meng Q (2018) Shallow structure of the Tangshan fault zone unveiled by dense seismic array and horizontal-to-vertical spectral ratio method. Phys Earth Planet Inter 281:46-54

Bensen GD, Ritzwoller MH, Barmin MP, Levshin AL, Lin F, Moschetti MP, Shapiro NM, Yang Y (2007) Processing seismic ambient noise data to obtain reliable broad-band surface wave dispersion measurements. Geophys J Int 169(3):1239-1260

Ben-Zion, Y., \& Zhu, L. (2002). Potency-magnitude scaling relations for southern California earthquakes with $1.0<\mathrm{M}$ L $<7.0$. Geophysical Journal International, 148(3), F1-F5.

Bobylev N (2010) Underground space in the Alexanderplatz area, Berlin: research into the quantification of urban underground space use. Tunn Undergr Space Technol 25(5):495-507

Bonnefoy-Claudet S, Cotton F, Bard PY (2006) The nature of noise wavefield and its applications for site effects studies: a literature review. Earth Sci Rev 79(3-4):205-227

Bora N, Biswas R, Malischewsky P (2020) Imaging subsurface structure of an urban area based on diffusefield theory concept using seismic ambient noise. Pure Appl Geophys 177(10):4733-4753

Boué P, Denolle M, Hirata N, Nakagawa S, Beroza GC (2016) Beyond basin resonance: characterizing wave propagation using a dense array and the ambient seismic field. Geophys J Int 206(2):1261-1272

Brenguier F, Boué P, Ben-Zion Y, Vernon F, Johnson CW, Mordret A, Lecocq T (2019) Train traffic as a powerful noise source for monitoring active faults with seismic interferometry. Geophys Res Lett 46(16):9529-9536

Bruno PPG, Rapolla A (1999) Study of the sub-surface structure of Somma-Vesuvius (Italy) by seismic reflection data. J Volcanol Geoth Res 92(3-4):373-387

Chapman CH (1978) A new method for computing synthetic seismograms. Geophys J Int 54(3):481-518

Chen X, Zhang H, Zhou C, Pang J, Xing H, Chang X (2021) Using ambient noise tomography and MAPS for high resolution stratigraphic identification in Hangzhou urban area. J Appl Geophys 189:104327

Cheng F, Xia J, Xu Z, Hu Y, Mi B (2018) Frequency-wavenumber (fk)-based data selection in high-frequency passive surface wave survey. Surv Geophys 39(4):661-682

Dou S, Lindsey N, Wagner AM, Daley TM, Freifeld B, Robertson M, Peterson J, Ulrich C, Martin E, AjoFranklin JB (2017) Distributed acoustic sensing for seismic monitoring of the near surface: a trafficnoise interferometry case study. Sci Rep 7(1):1-12

Dou, S., Pevzner, R., Ajo-Franklin, J., Daley, T., Robertson, M., Wood, T., Correa, J., Tertyshnikov, K., Urosevic, M., Gurevich, B., \& Freifeld, B. (2016). Surface orbital vibrator (SOV) and fiber-optic DAS: Field demonstration of economical, continuous land seismic time-lapse monitoring from the Australian CO2CRC Otway site. In SEG Technical Program Expanded Abstracts (Vol. 35, pp. 5552-5556).

Dumont, V., Tribaldos, V. R., Ajo-Franklin, J., \& Wu, K. (2020, December). Deep learning for surface wave identification in distributed acoustic sensing data. In 2020 IEEE International Conference on Big Data (Big Data) (pp. 1293-1300).

Fang, G., Li, Y. E., Zhao, Y., \& Martin, E. R. (2020). Urban near-surface seismic monitoring using distributed acoustic sensing. Geophysical Research Letters, 47(6), https://doi.org/10.1029/2019GL086115.

Foti S, Parolai S, Albarello D, Picozzi M (2011) Application of surface-wave methods for seismic site characterization. Surv Geophys 32(6):777-825

Galetti E, Curtis A (2012) Generalised receiver functions and seismic interferometry. Tectonophysics 532:1-26

Guan B, Mi B, Zhang H, Liu Y, Xi C, Zhou C (2021) Selection of noise sources and short-time passive surface wave imaging-A case study on fault investigation. J Appl Geophys 194:104437

Halliday D, Curtis A, Kragh E (2008) Seismic surface waves in a suburban environment: active and passive interferometric methods. Lead Edge 27(2):210-218 
Herrmann RB (2013) Computer programs in seismology: an evolving tool for instruction and research. Seismol Res Lett 84(6):1081-1088

Jakkampudi S, Shen J, Li W, Dev A, Zhu T, Martin ER (2020) Footstep detection in urban seismic data with a convolutional neural network. Lead Edge 39(9):654-660

Jousset P, Reinsch T, Ryberg T, Blanck H, Clarke A, Aghayev R, Krawczyk CM (2018) Dynamic strain determination using fibre-optic cables allows imaging of seismological and structural features. Nat Commun 9(1):1-11

Krawczyk CM, Polom U, Trabs S, Dahm T (2012) Sinkholes in the city of Hamburg-new urban shear-wave reflection seismic system enables high-resolution imaging of subrosion structures. J Appl Geophys 78:133-143

Kuponiyi AP, Kao H (2021) Temporal variation in cultural seismic noise and noise correlation functions during COVID-19 lockdown in Canada. Seismol Res Lett 92(5):3024-3034

Lecocq T, Hicks SP, Van Noten K, Van Wijk K, Koelemeijer P, De Plaen RS, Xiao H (2020) Global quieting of high-frequency seismic noise due to COVID-19 pandemic lockdown measures. Science 369(6509):1338-1343

Lehujeur M, Vergne J, Maggi A, Schmittbuhl J (2016) Ambient noise tomography with non-uniform noise sources and low aperture networks: case study of deep geothermal reservoirs in northern Alsace, France. Geophys Suppl Mon Notices Royal Astron Soci 208(1):193-210

Li C, Yao H, Fang H, Huang X, Wan K, Zhang H, Wang K (2016a) 3D near-surface shear-wave velocity structure from ambient-noise tomography and borehole data in the Hefei urban area China. Seismol Res Lett 87(4):882-892

Li Z, Zhou J, Wu G, Wang J, Zhang G, Dong S, Pan L, Yang Z, Gao L, Ma Q, Rem H, Chen X (2021) CCFJpy: a python package for extracting overtone surface-wave dispersion from seismic ambient-noise cross correlation. Seismol Res Lett 92(5):3179-3186

Li, Q., Wan, J., \& Cao, G. (2016b). Framework Design of Urban Traffic Monitoring and Service System. In Proceedings of the 2015 International Conference on Electrical and Information Technologies for Rail Transportation (pp. 737-743). Springer, Berlin, Heidelberg.

Liang F, Wang Z, Li H, Liu K, Wang T (2019) Near-surface structure of downtown Jinan, China: application of ambient noise tomography with a dense seismic array. J Environ Eng Geophys 24(4):641-652

Lin FC, Li D, Clayton RW, Hollis D (2013) High-resolution 3D shallow crustal structure in long beach, California: application of ambient noise tomography on a dense seismic array. Geophysics 78(4):Q45-Q56

Lin R, Zeng X, Song Z, Xu S, Hu J, Sun T, Wang B (2020) Distributed acoustic sensing for imaging shallow structure II: ambient noise tomography. Chin J Geophys 63(4):1622-1629

Lindsey NJ, Martin ER, Dreger DS, Freifeld B, Cole S, James SR, Biondi BL, Ajo-Franklin JB (2017) Fiber-optic network observations of earthquake wavefields. Geophys Res Lett 44(23):11-792

Lindsey, N. J., Yuan, S., Lellouch, A., Gualtieri, L., Lecocq, T., \& Biondi, B. (2020). City-scale dark fiber DAS measurements of infrastructure use during the COVID-19 pandemic. Geophy Res Lett, 47(16). https://doi.org/10.1029/2020GL089931.

Liu Y, Chong J, Ni SD (2011) Near surface wave velocity structure in Chinese capital region based on borehole seismic records. Acta Seismol Sinica 33:342-350

Luo Y, Xia J, Miller RD, Xu Y, Liu J, Liu Q (2008) Rayleigh-wave dispersive energy imaging using a highresolution linear radon transform. Pure Appl Geophys 165(5):903-922

Ma Z, Qian R (2020) Overview of seismic methods for urban underground space. Interpretation 8(4):U19-U30

Martin ER, Huot F, Ma Y, Cieplicki R, Cole S, Karrenbach M, Biondi BL (2018) A seismic shift in scalable acquisition demands new processing: fiber-optic seismic signal retrieval in urban areas with unsupervised learning for coherent noise removal. IEEE Signal Process Mag 35(2):31-40

McMechan GA, Yedlin MJ (1981) Analysis of dispersive waves by wave field transformation. Geophysics 46(6):869-874

McNamara DE, Buland RP (2004) Ambient noise levels in the continental United States. Bull Seismol Soc Am 94(4):1517-1527

Mi B, Xia J, Bradford JH, Shen C (2020) Estimating near-surface shear-wave-velocity structures via multichannel analysis of Rayleigh and Love waves: an experiment at the boise hydrogeophysical research site. Surv Geophys 41(2):323-341

Nakata N, Chang JP, Lawrence JF, Boué P (2015) Body wave extraction and tomography at Long Beach, California, with ambient-noise interferometry. Journal of Geophysical Research: Solid Earth 120(2):1159-1173

Nakata N, Snieder R, Tsuji T, Larner K, Matsuoka T (2011) Shear wave imaging from traffic noise using seismic interferometry by cross-coherence. Geophysics 76(6):SA97-SA106 
Nayak A, Ajo-Franklin J (2021) Distributed acoustic sensing using dark fiber for array detection of regional earthquakes. Seismol Res Lett 92(4):2441-2452

Park CB, Miller RD, Xia J (1999) Multichannel analysis of surface waves. Geophysics 64(3):800-808

Park CB, Miller RD, Xia J, Ivanov J (2007) Multichannel analysis of surface waves (MASW) - active and passive methods. Lead Edge 26(1):60-64

Parker LM, Thurber CH, Zeng X, Li P, Lord NE, Fratta D, Feigl KL (2018a) Active-source seismic tomography at the brady geothermal field, nevada, with dense nodal and fiber-optic seismic arrays. Seismol Res Lett 89(5):1629-1640

Parker LM, Thurber CH, Zeng X, Li P, Lord NE, Fratta D, Wang HF, Robertson MC, Thomas AM, Karplus MS, Nayak A, Feigl KL (2018b) Active-source seismic tomography at the brady geothermal field, nevada, with dense nodal and fiber-optic seismic arrays. Seismol Res Lett 89(5):1629-1640

Parker, T., Shatalin, S., \& Farhadiroushan, M. (2014). Distributed acoustic sensing-a new tool for seismic applications. first break, 32(2), 61-69.

Qiu, H., Niu, F., \& Qin, L. (2020). Denoising surface waves extracted from ambient noise using threestation interferometry: methodology and application to 1-D linear array. J Geophys Res: Solid Earth, https://doi.org/10.1029/2021JB021712.

Retailleau L, Beroza GC (2021) Towards structural imaging using seismic ambient field correlation artefacts. Geophys J Int 225(2):1453-1465

Rix, G. J., and E. A. Leipski, 1991, Accuracy and resolution of surface wave inversion. Recent advances in instrumentation, data acquisition and testing in soil dynamics: Proceedings of Sessions Sponsored by the Geotechnical Engineering Division of the American Society of Civil Engineers Inc., Publication of American Society of Civil Engineers.

Roy KS, Sharma J, Kumar S, Kumar MR (2021) Effect of coronavirus lockdowns on the ambient seismic noise levels in Gujarat, northwest India. Sci Rep 11(1):1-13

Sambridge M (1999b) Geophysical inversion with a neighbourhood algorithm-II Appraising the ensemble. Geophys J Int 138(3):727-746

Sambridge M (1999a) Geophysical inversion with a neighbourhood algorithm-I. Searching a parameter space. Geophys J Int 138(2):479-494

Schimmel M, Gallart J (2007) Frequency-dependent phase coherence for noise suppression in seismic array data. J Geophy Res Solid Earth. https://doi.org/10.1029/2006JB004680

Schippkus S, Garden M, Bokelmann G (2020) Characteristics of the ambient seismic field on a Large-N seismic array in the Vienna Basin. Seismol Soci Am 91(5):2803-2816

Shapiro NM, Campillo M, Stehly L, Ritzwoller MH (2005) High-resolution surface-wave tomography from ambient seismic noise. Science 307(5715):1615-1618

She Y (2021) Study on fine shallow subsurface structure based on airgun source and ambient noise methods. PHD thesis. University of Science and Technology of China

She Y, Yao H, Wang W, Liu B (2019) Characteristics of seismic wave propagation in the binchuan region of Yunnan using a dense seismic array and large volume airgun shots. Earthq Res China 2:174-185

Shragge, J., Yang, J., Issa, N. A., Roelens, M., Dentith, M., \& Schediwy, S. (2019). Low-frequency ambient distributed acoustic sensing (DAS): Useful for subsurface investigation?. In SEG Technical Program Expanded Abstracts 2019 (pp. 963-967). Society of Exploration Geophysicists.

Song Z, Zeng X, Thurber CH, Wang HF, Fratta D (2018) Imaging shallow structure with active-source surface wave signal recorded by distributed acoustic sensing arrays. Earthq Sci 31:208-214

Song Z, Zeng X, Xu S, Hu J, Sun T, Wang B (2020) Distributed acoustic sensing for imaging shallow structure I: active source survey. Chin J Geophys 63(2):532-540

Song Z, Zeng X, Wang B, Yang J, Li X, Wang HF (2021) Distributed acoustic sensing using a largevolume airgun source and internet fiber in an urban area. Seismol Res Lett 92(3):1950-1960

Spica, Z. J., Perton, M., Martin, E. R., Beroza, G. C., \& Biondi, B. (2020). Urban seismic site characterization by fiber-optic seismology. J Geophys Res: Solid Earth, https://doi.org/10.1029/2019JB0186 56.

Sun T, Wang W, Wang B (2019) Using a dense array and HVSR to obtain the shallow structure of the Binchuan Basin. Acta Geologica Sinica-English Ed 93:330-331

Tran KT, McVay M, Faraone M, Horhota D (2013) Sinkhole detection using 2D full seismic waveform tomography. Geophysics 78(5):R175-R183

Wang J, Wu G, Chen X (2019) Frequency-Bessel transform method for effective imaging of highermode Rayleigh dispersion curves from ambient seismic noise data. J Geophys Res: Solid Earth 124(4):3708-3723

Wang X, Williams EF, Karrenbach M, Herráez MG, Martins HF, Zhan Z (2020) Rose Parade seismology: signatures of floats and bands on optical fiber. Seismol Res Lett 91(4):2395-2398 
Wang X, Zhan Z, Williams EF, Herráez MG, Martins HF, Karrenbach M (2021b) Ground vibrations recorded by fiber-optic cables reveal traffic response to COVID-19 lockdown measures in Pasadena. Calif Commun Earth Environ 2(1):1-9

Wang B, Zeng X, Song Z, Li X, Yang J (2021c) Seismic observation and subsurface imaging using an urban telecommunication optic-fiber cable. Chin Sci Bull. https://doi.org/10.1360/TB-2020-1427

Wang, X., Zhan, Z., Zhong, M., Persaud, P., \& Clayton, R. W. (2021a). Urban basin structure imaging based on dense arrays and bayesian array-based coherent receiver functions. J Geophys Res: Solid Earth, https://doi.org/10.1029/2021JB022279.

Williams EF, Fernández-Ruiz MR, Magalhaes R, Vanthillo R, Zhan Z, González-Herráez M, Martins HF (2021) Scholte wave inversion and passive source imaging with ocean-bottom DAS. Lead Edge 40(8):576-583

Xia J, Miller RD, Park CB (1999) Estimation of near-surface shear-wave velocity by inversion of rayleigh waves. Geophysics 64(3):691-700

Xia J, Miller RD, Park CB, Tian G (2003) Inversion of high frequency surface waves with fundamental and higher modes. J Appl Geophys 52(1):45-57

Xia J, Xu Y, Miller RD (2007) Generating an image of dispersive energy by frequency decomposition and slant stacking. Pure Appl Geophys 164(5):941-956

Yan Y, Sun C, Lin T, Wang J, Yang J, Wu D (2021) Surface-wave simulation for the continuously moving seismic sources. Seismol Res Lett 92(4):2429-2440

Yao H, Van Der Hilst RD (2009) Analysis of ambient noise energy distribution and phase velocity bias in ambient noise tomography, with application to SE Tibet. Geophys J Int 179(2):1113-1132

Zeng X, Thurber CH (2016) A graphics processing unit implementation for time-frequency phase-weighted stacking. Seismol Res Lett 87(2A):358-362

Zeng X, Lancelle C, Thurber C, Fratta D, Wang H, Lord N, Chalari A, Clarke A (2017) Properties of noise cross-correlation functions obtained from a distributed acoustic sensing array at Garner Valley, California. Bull Seismol Soc Am 107(2):603-610

Zeng X, Ni S (2010) A persistent localized microseismic source near the Kyushu Island Japan. Geophys Res Lett. https://doi.org/10.1029/2010GL045774

Zhan Z (2020) Distributed acoustic sensing turns fiber-optic cables into sensitive seismic antennas. Seismol Res Lett 91(1):1-15

Zhang Y, Li YE, Zhang H, Ku T (2019) Near-surface site investigation by seismic interferometry using urban traffic noise in Singapore. Geophysics 84(2):B169-B180

Zhang S, Feng L, Ritzwoller MH (2020a) Three-station interferometry and tomography: coda versus direct waves. Geophys J Int 221(1):521-541

Zhang YP, Wang BC, Lin GC, Wang WT, Yang W, Wu ZH (2020b) Upper crustal velocity structure of Binchuan, Yunnan revealed by dense array local seismic tomography. Chin J Geophys 63(9):3292-3306

Zhou C, Xia J, Pang J, Cheng F, Chen X, Xi C, Zhou C (2021) Near-surface geothermal reservoir imaging based on the customized dense seismic network. Surv Geophys 42(3):673-697

Zhu T, Stensrud DJ (2019) Characterizing thunder-induced ground motions using fiber-optic distributed acoustic sensing array. J Geophys Res: Atmos 124(23):12810-12823

Publisher's Note Springer Nature remains neutral with regard to jurisdictional claims in published maps and institutional affiliations.

\section{Authors and Affiliations}

\section{Zhenghong Song $^{1,2} \cdot$ Xiangfang Zeng $^{1} \cdot$ Jun $\mathrm{Xie}^{1} \cdot$ Feng Bao $^{1} \cdot$ Gongbo Zhang $^{1}$}

Xiangfang Zeng

zengxf@whigg.ac.cn

1 State Key Laboratory of Geodesy and Earth's Dynamics, Innovation Academy for Precision Measurement Science and Technology, Chinese Academy of Sciences, Wuhan 430077, China

2 School of Earth and Space Sciences, University of Science and Technology of China, Hefei 230026, China 